\title{
Dades de plantes al·lòctones per a l'est de la península Ibèrica
}

\author{
R. SENAR ${ }^{1} \&$ S. CARDERO ${ }^{2}$ \\ ${ }^{1}$ c. Cèsar Cataldo, 13, ES-12580 Benicarló, Castelló, Espanya \\ 2 av. Josep Tarradellas, 148, 4-B, ES-43870 Amposta, Tarragona, Espanya
}

ORCID iD. R. SENAR: https://orcid.org/0000-0003-3316-897X, S. CARDERO: https://orcid.org/0000-0002-8129-2265

Autor per a la correspondència: R. Senar (romasenar@gmail.com)

Editors: N. Nualart \& J. López-Pujol

Rebut 3 febrer 2019; acceptat 29 maig 2019; publicat on line 15 octubre 2019

\begin{abstract}
Data of alien plants for the east of Iberian Peninsula.- With the observations of the last years in the east of the Iberian Peninsula (specifically in Catalonia, Valencian Country and the Teruel province), records of 41 naturalized or casual alien plants are reported. It is worth noting Annona cherimola and Manihot grahamii that are reported for first time in the Iberian flora; Echinopsis pachanoi and Hydrocotyle verticillata for Catalonia; Solandra maxima for Valencian Country. Opuntia pestifer must be excluded from the Valencian flora, and it is confirmed that the previous data correspond to Opuntia aurantiaca. In addition, new localities of Acacia karroo, Cylindropuntia kleiniae, Euphorbia tirucalli, Leucaena leucocephala, Lophocereus marginatus, Nicandra physalodes, Pelargonium inquinans, Physalis peruviana, Podranea ricasoliana, Sedum pachyphyllum, Senna corymbosa, Tradescantia pallida and Tradescantia sillamontana, interesting and few known species in the eastern Iberian alien flora are provided.
\end{abstract}

Key words: alien plants; Catalonia; chorology; Iberian Peninsula; Teruel; Valencian Country; vascular plants.

\section{Resumen}

Datos de plantas alóctonas para el este de la Península ibÉRICA. - Con las observaciones de los últimos años en el este de la península ibérica (concretamente en Cataluña, País Valenciano y la provincia de Teruel), se aportan un conjunto de datos corológicos de 41 plantas alóctonas naturalizadas u ocasionales. Cabe destacar Annona cherimola y Manihot grahamii que se citan por primera vez en la flora ibérica; Echinopsis pachanoi y Hydrocotyle verticillata para Cataluña; Solandra maxima en el País Valenciano. Se tiene que excluir Opuntia pestifer de la flora valenciana, ya que se confirma que las citas anteriores corresponden a Opuntia aurantiaca. Además, se aportan nuevas localidades de Acacia karroo, Cylindropuntia kleiniae, Euphorbia tirucalli, Leucaena leucocephala, Lophocereus marginatus, Nicandra physalodes, Pelargonium inquinans, Physalis peruviana, Podranea ricasoliana, Sedum pachyphyllum, Senna corymbosa, Tradescantia pallida y Tradescantia sillamontana, táxones interesantes y poco conocidos en la flora alóctona del este ibérico.

Palabras clave: Cataluña; corología; País Valenciano; península ibérica; plantas alóctonas; plantas vasculares; Teruel.

\section{Resum}

Dades de plantes al Lòctones Per a l'est de la península Ibèrica. - Amb les observacions dels darrers anys fetes a l'est de la península Ibèrica (concretament a Catalunya, País Valencià i la província de Terol), s'aporten un conjunt de dades corològiques de 41 plantes al·lòctones naturalitzades o ocasionals. Cal destacar Annona cherimola i Manihot grahamii que es citen per primera vegada a la flora ibèrica; Echinopsis pachanoi i Hydrocotyle verticillata per a Catalunya; Solandra maxima per al País Valencià. Cal excloure Opuntia pestifer de la flora valenciana, ja que es confirma que les cites anteriors corresponen a Opuntia aurantiaca. A més a més, s'aporten noves localitats de Acacia karroo, Cylindropuntia kleiniae, Euphorbia tirucalli, Leucaena leucocephala, Lophocereus marginatus, Nicandra physalodes, Pelargonium inquinans, Physalis peruviana, Podranea ricasoliana, Sedum pachyphyllum, Senna corymbosa, Tradescantia pallida i Tradescantia sillamontana, tàxons interessants i poc coneguts a la flora al·lòctona de l'est ibèric.

Paraules clau: Catalunya; corologia; País Valencià; península Ibèrica; plantes al·lòctones; plantes vasculars; Terol. 
Cómo citar este artículo / Citation

Senar, R. \& Cardero, S. 2019. Dades de plantes al·lòctones per a l'est de la península Ibèrica. Collectanea Botanica 38: e009. https://doi.org/10.3989/collectbot.2019.v38.009

Copyright

(C) 2019 CSIC. This is an open-access article distributed under the terms of the Creative Commons Attribution 4.0 International (CC BY 4.0) License.

\section{INTRODUCCIÓ}

La globalització, la facilitat de mobilitat i el lliure comerç suposen avui en dia grans avantatges per al desenvolupament humà. Aquests fets han facilitat el transport d'espècies al lòctones a moltes regions del planeta i sense parar compte ens trobem envoltats de multitud d'espècies forànies, ja siguen amb finalitats ornamentals, agrícoles, ramaderes o industrials. Les causes del salt d'aquestes espècies cultivades cap al medi natural poden ser molt variades, simplement com dispersió natural de llavors d'espècies conreades en jardins pròxims, ús d'espècies en la consolidació de talussos o cultius; com accidentals derivats del transport, importació de substrats, adobs orgànics, etc. (Casasayas, 1989). També la mala pràctica de llençar restes de podes i de jardineria. Siga qualsevol la via de salt d'una espècie forània al medi natural, el seu establiment es veu afavorit per la degradació dels hàbitats i pel canvi climàtic, que, amb l'increment de temperatures, s'afavoreix l'aclimatació de certes espècies als nostres ecosistemes. La introducció d'éssers vius fora de la seua àrea de distribució natural suposa, després de la destrucció dels hàbitats, el segon problema ambiental que afecta a la biosfera a escala global. La pèrdua de biodiversitat, canvis i alteracions en els cicles biogeoquímics, l'homogeneïtzació dels ecosistemes, i inclús l'extinció d'espècies natives, són les conseqüències més negatives (Sanz Elorza et al., 2004).

La finalitat d'aquest treball és contribuir al coneixement de la flora al lòctona dins de l'espai que ens ocupa, la zona litoral de l'est ibèric, especialment Catalunya, el País Valencià, així com alguns pobles d'Aragó. Per això, fruit de les observacions de camp, s'aporten un conjunt de dades de plantes al·lòctones, trobades naturalitzades o bé ocasionals. Algunes d'elles suposen nous xenòfits per a un territori concret (comarca, província o fins i tot noves per a la flora ibèrica). D'altres són espècies de les quals es coneixen poques localitats i és millora la informació sobre elles, aportant noves citacions que amplien la seua zona de distribució.
El conjunt de flora al $\cdot$ lòctona ha sigut tradicionalment poc tractada pels estudis botànics. La dificultat per la identificació de les espècies i el poc valor que se'ls ha donat, han fet que fins les darreres dècades no s'hi troben gaire treballs dedicats a aquests tàxons. Avui en dia però, la balança es va anivellant i ja s'hi troba un conjunt prou abundant de bibliografia, bases de dades $i$ webs especialitzades en el tractament i corologia d'espècies al·lòctones.

\section{MATERIAL I MÈTODES}

El conjunt de dades de les espècies tractades es citen per ordre alfabètic segons l'espècie. A continuació s'indica la família i s'enumeren les localitats per província, comarca, municipi, i paratge, amb les coordenades UTM (d'1 $\times 1 \mathrm{~km}$ expressat amb el sistema de referència ETRS89), l'altitud, l'hàbitat i data de l'observació. Seguidament, es comenten alguns aspectes de les poblacions si escau, amb una breu informació de les generalitats de l'espècie (zona d'origen, distribució, usos i problemàtica). També per a cada tàxon s'aporten les referències bibliogràtiques o informació anterior dins del territori estudiat, o bé d'altres zones geogràtiques. En algunes espècies s'indica també la sinonímia que s'ha trobat a les diferents obres consultades per referir-se al mateix tàxon. De les localitats que s'han recollit plecs testimonis, aquests s'han dipositat a l'herbari VAL, al Museu de les Terres de l'Ebre d'Amposta (MTTE) o a l'herbari personal (herb. pers. RS). Pel que fa a les novetats florístiques, s'indiquen amb un asterisc $(*)$ davant de l'àmbit geogràfic per al qual és novetat (província o comarca), o bé davant del nom de l'espècie quan aquesta siga novetat estatal.

En alguns casos per tal de conèixer la distribució de les espècies a Catalunya i el País Valencià, s'acudeix al Sistema de Información de Plantas de España (ANTHOS, 2018), al Banc de Dades de la Biodiversitat de Catalunya (Font, 2018) i al Banc de Dades de la Biodiversitat de la Comunitat 
Valenciana (BDBCV, 2018), en endavant ANTHOS, BDBC i BDBCV respectivament.

\section{RESULTATS}

Acacia karroo Hayne, Getreue Darstell. Gew. 10: 33 (1827) (Leguminosae).

$\equiv$ Vachellia karroo (Hayne) Banfi \& Galasso in Atti Soc. Ital. Sci. Nat. Mus. Civico Storia Nat. Milano 149: 149 (2007).

Castelló, Baix Maestrat: Peníscola, serra d'Irta, pla dels Pitxells, pr. el Volant, 31TBE7768, 5 m, coscollar xèric sobre roquers calcaris, 27.VI.2018, R. Senar (herb. pers. RS 11074); Sant Jordi, pou de Muntells, 31TBE7287, $255 \mathrm{~m}$, marges de cultius i finques ermes, 4.V.2011, R. Senar. *Tarragona, Montsià: Alcanar, Cases d'Alcanar, vora N-340, 31TBE9092, $10 \mathrm{~m}$, marge de la carretera i finques de cultiu, 2.VII.2011, R. Senar (herb. pers. RS 2722); ibid., 11.IX.2016, R. Senar (herb. pers. RS 7486).

En totes les localitats s'han trobat diversos exemplars de diferents edats formant cert conjunt intricat arbustiu. De moment aquestes poblacions ocupen superfícies molt reduïdes $\left(10-20 \mathrm{~m}^{2}\right)$, però no es descarta que puguen envair altres ecosistemes pròxims en un futur, tal com passa amb altres acàcies amb un comportament invasor confirmat, com A. dealbata Link, A. farnesiana (L.) Willd. o A. saligna (Labill.) H. L. Wendl.

Acacia karroo és una lleguminosa originària de diversos països sud-africans (Barnes et al., 1996). Pel que respecta a Catalunya i el País Valencià la seua presència és escassa, tan sols es coneixen unes poques cites anteriors a les províncies de Barcelona, Alacant i Castelló (Pyke, 2008; Sanz Elorza et al., 2011; BDBC). A la província de Castelló ha estat citada únicament dins de la quadrícula BE77, segons les dades que es recullen al BDBCV. Amb tot això, s'aporten diverses localitats noves que amplien substancialment l'àrea de distribució d'aquesta espècie.

Aeonium arboreum (L.) Webb \& Berthel., Hist. Nat. Iles Canaries 3(2,1): 185 (1840) (Crassulaceae).

Castelló, Baix Maestrat: Peníscola, serra d'Irta, barranc de la font Nova, 31TBE7668, $55 \mathrm{~m}$, herbassars ruderals, 20.XI.2015, R. Senar (herb. pers. RS 5777); ibid., voltants de la urbanització Cap Blanc, 31TBE7769, 40 m, solar per edificar, 20.I.2019, R. Senar.

Espècie que apareix de forma molt freqüent cultivada com a ornamental. La seua capacitat d'arrelar a partir d'esqueixos és la via principal d'expansió a les localitats on ha sigut citada com al·lòctona (Guillot et al., 2008b). Dins del País Valencià està present a les tres províncies de forma mitjanament comuna (Sanz Elorza et al., 2011). A Castelló va ser advertida per Roselló $(2008 a, b)$ en Borriana $\mathrm{i}$ indicat posteriorment en diverses localitats més, a les quals afegim dos punts nous segons Royo (2006), Senar (2016) i el BDBCV.

Aloe vera (L.) Burm. f., Fl. Indica: 83 (1768) (Asphodelaceae).

Castelló, Alt Palància: Assuévar, part alta del poble, 30SYK2512, $300 \mathrm{~m}$, ambients ruderals, 22.XI.2015, R. Senar \& A. Torres. Baix Maestrat: Canet lo Roig, mas de Plajové, 31TBE6191, 400 m, erms de secà, 28.VI.2018, R. Senar. Plana Alta: Cabanes, ermita d'Albalat dels Ànecs, vora corrals, 31TBE5750, $30 \mathrm{~m}$, coscollars calcigats, 6.XII.2016, P. Gumbau \& R. Senar.

Cultivada des de temps antics per tot el Mediterrani i d'origen incert, apareix naturalitzada en zones pròximes als seus cultius (Guillot et al., 2008c). Va ser advertida com al·lòctona al País Valencià l'any 1886 (Sanz Elorza et al., 2011) i amb el temps s'han anat sumant noves localitats a les tres províncies. S'aporten algunes cites més que cal afegir a les ja conegudes per a la província de Castelló segons la bibliografia consultada (Samo, 1995; Guillot \& Meer, 2005; Senar, 2016; BDBCV).

Alternanthera caracasana Kunth in Humb., Bonpl. \& Kunth, Nov. Gen. Sp. 2(7): 205 (1818) (Amaranthaceae).

Castelló, Alt Palància: Xóvar, 30SYK2914, 350 $\mathrm{m}$, herbassars nitròfils pels carrers de la població, 22.XI.2015, R. Senar \& A. Torres (herb. pers. RS 5793, VAL 228784).

Aquest tàxon neotropical ha sigut indicat en vàries localitats de Castelló (Samo, 1995; Tirado, 1998; Aparicio, 2002; Royo, 2006; Senar, 2016). Dins del BDBCV trobem que la quadrícula YK21 apareix ja donada per a aquesta espècie en Soneixa i Sogorb, per tant s'afegeix una localitat més dins d'aquesta quadrícula. 
*Annona cherimola Miller, Gard. Dict. 5 (1768) (Annonaceae).

Castelló, Plana Alta: Orpesa del Mar, via verda, pr. torre Colomera, 31TBE5338, $15 \mathrm{~m}$, herbassar ruderal baix cingles calcaris, 7.IX.2016., V. J. Arán, P. Gumbau \& R. Senar (herb. pers. RS 7478, VAL 230388).

Es descarta la procedència d'un antic cultiu d'aquest exemplar, ja que el seu emplaçament es troba a la base dels talussos de l'antiga via del tren, entre badalls de roca i lluny de zones de cultius, però $\mathrm{amb}$ activitat antròpica evident per ser zona de pas de l'actual via verda. L'exemplar és juvenil, d'uns $2 \mathrm{~m}$ i tot apunta a un origen assilvestrat, procedent de llavor.

La xirimoia (Annona cherimola) és un arbre fruiter neotropical introduit al sud d'Espanya l'any 1757. El seu cultiu es va consolidar al segle XX a Canàries i a la costa mediterrània d'Andalusia, i aquesta darrera regió és la principal productora mundial d'aquesta fruita (Rosell et al., 1997). Encara que de manera més minoritària, també es cultiva en altres regions del litoral peninsular amb clima càlid. S'han vist cultius d'exemplars aïllats en hortes de les comarques del Montsià, el Baix Maestrat o la Plana (obs. pers.), quedant patent que la benevolència climàtica d'aquesta regió litoral permet el bon desenvolupament de la xirimoia, per això el salt al medi natural no resulta estrany.

A Europa $A$. cherimola s'ha detectat com al lòctona al medi natural únicament a Itàlia, segons les dades recollides en Celesti-Grapow et al. (2009) i DAISIE (2018). Pel que respecta a la península Ibèrica, no s'han trobat citacions anteriors. Únicament dins del treball de Laguna \& Mateo (2001) s'adverteix la presència de l'espècie per a la flora al·lòctona valenciana. Aquests autors situen $A$. cherimola dins d'un conjunt de tàxons cultivats $\mathrm{i}$ en procés de naturalització, dels quals no hi ha suficients evidències de la seua instal·lació autònoma al medi natural. Pareix que posteriorment no han hagut evidències de tal procés de naturalització al territori, ja que a les obres posteriors d'identificació de flora valenciana no s'hi fa cap menció al respecte (Mateo \& Crespo, 2003, 2009, 2014). L'espècie no apareix indicada al BDBCV per al País Valencià, tampoc en ANTHOS, Castroviejo (1986-2018), ni en Sanz Elorza et al. (2004) per a la resta d'Espanya o la península. Amb aquesta informació s'aporta la primera localitat confirmada
d'A. cherimola com al·lòctona a la península Ibèrica.

Bidens pilosa L., Sp. Pl. 2: 832 (1753) (Compositae).

Castelló, Baix Maestrat: Alcalà de Xivert, Alcossebre, vores d'urbanitzacions, 31TBE6959, 25 $\mathrm{m}$, herbassars ruderals calcaris, 31.XII.2018, $R$. Senar; Benicarló, el Barranquet, junt al camí d'Artola, 31TBE8076, 8 m, codolar amb humitat, 16.XI.2015, R. Senar (herb. pers. RS 5758, VAL 228781); ibid., el Povet, vora N-340, 31TBE8277, 10 m, herbassar nitròfil vora cunetes, 21.I.2016, R. Senar (herb. pers. RS 5860, VAL 230418); Santa Magdalena de Polpis, vora l'autopista AP-7, pr. cementeri, 31TBE7170, $150 \mathrm{~m}$, herbassar subnitròfil amb humitat estacional, 9.III.2018, R. Senar (herb. pers. RS 9889); ibid., el Saltet, vora camí a l'autopista AP-7, 31TBE7371, $140 \mathrm{~m}$, herbassar subnitròfil amb humitat estacional, 10.XI.2018, R. Senar.

L'espècie resulta més comuna per a la resta de províncies valencianes que per a Castelló (Roselló \& Peris, 1990; Bolòs et al., 2008: mapa 3619; Mateo, 2013; BDBCV). S'aporten una sèrie de cites per a aquesta zona geogràifica, on la presència d'aquesta composta pareix més freqüent del que es pensava.

Bryophyllum delagoense (Eckl. \& Zeyh.) Schinz in Mém. Herb. Boissier 10: 38 (1900) (Crassulaceae).

$\equiv$ Kalanchoe delagoensis Eckl. \& Zeyh, Enum. Pl. Afr. Austral. 3: 305 (1836).

= Kalanchoe tubiflora Raym.-Hamet in Beih. Bot. Centralbl. 29(2): 41 (1912).

Castelló, *Alcalatén: les Useres, voltants del poble, 30TYK4148, $370 \mathrm{~m}$, talussos ruderals calcaris, 14.II.2016, P. Gumbau, R. Senar \& A. Torres (herb. pers. RS 6002). Baix Maestrat: Peníscola, serra d'Irta, los Barrancs, pr. bassa de Singüesa, 31TBE7674, $80 \mathrm{~m}$, finques ermes sobre roquers calcaris, 9.XI.2018, R. Senar; ibid., pr. Puerto Azul, 31TBE7869, $2 \mathrm{~m}$, coscollars calcigats vora mar, 20.IX.2015, R. Senar (herb. pers. RS 5769).

Espècie exòtica usada com a ornamental, de presència escassa al medi natural però quan apareix ho fa formant grups densos. Són poques les citacions anteriors a la província de Castelló. Les primeres cites les trobem en Guillot et al. (2008b) i Roseló $(2008 a)$ per a la Plana Baixa. Posteriorment 
ha sigut aportada a les comarques de l'Alt i Baix Maestrat (Senar, 2016; BDBCV). Es desconeix cap citació anterior per a l'Alcalatén.

Bryophyllum $\times$ houghtonii (D. B. Ward) P. I. Forst. in Austrobaileya 7: 383 (2006) (Crassulaceae).

$\equiv$ Kalanchoe $\times$ houghtonii D. B. Ward in Cact. Succ. J. (Los Angeles) 78(2): 94 (2006).

Castelló, Alcalatén: Costur, mas d'Avall, 30TYK4045, $420 \mathrm{~m}$, sobre roquers calcaris, 14.II.2016, P. Gumbau, R. Senar \& A. Torres; les Useres, voltants del poble, 30TYK4148, $370 \mathrm{~m}$, ermots, 14.II.2016, P. Gumbau, R. Senar \& A. Torres (herb. pers. RS 6003). Baix Maestrat: Peníscola, serra d'Irta, barranc de la font Nova, 31TBE7668, 55 m, ambients ruderals, 20.XI.2015, R. Senar (herb. pers. RS 5778); ibid., Puerto Azul, 31TBE7869, 2 m, coscollars vora mar, 20.XI.2015, R. Senar (herb. pers. RS 5770). Tarragona, Montsià: Mas de Barberans, carretera local que voreja el barranc de la Galera per l'esquerra, prop de la carretera TV-3421, 31 TBF7809, $320 \mathrm{~m}$, paret de pedra en sec vora conreus d'oliveres, 20.V.2017, S. Cardero.

Híbrid que va ser originat de forma artificial als EUA per A. D. Houghton usant parentals originaris de Madagascar - Bryophyllum daigremontianum (Raym.-Hamet \& H. Perrier) A. Berger $\times$ Bryophyllum delagoense (Eckl. \& Zeyh.) Schinz-, i es desconeix si tal hibridació es dona de forma natural a la seua zona d'origen (Hannan-Jones \& Playford, 2002). Bryophyllum $\times$ houghtonii produeix propàguls foliars, a l'igual que els seus congèneres, facilitant la seua expansió al medi natural. Mostra un caràcter invasor ocupant, amb gran densitat d'individus, els llocs on apareix i desplaça les espècies autòctones. Tot $\mathrm{i}$ això, no figura al catàleg de plantes invasores d'Espanya (Sanz Elorza et al., 2004), encara que la legislació valenciana sí que l'inclou com a espècie exòtica invasora (ORDRE 10/2014, de 26 de maig).

S'aporten un conjunt de localitats més d'aquest xenòfit a la nostra flora, segons Guillot et al. (2008b), Roselló (2008b), Laguna et al. (2014b), Senar (2016), Mesquida et al. (2017) i el BDBCV.

Cenchrus setaceus (Forssk.) Morrone in Ann. Bot. (Oxford) 106: 109 (2010) (Gramineae).

$\equiv$ Pennisetum setaceum (Forssk.) Chiov. in Boll. Soc. Bot. Ital. 1923: 113 (1923).

Castelló, *Alcalatén: Alcora, polígon industrial les Foies-Ferreres, 30TYK3938, 275 m, herbassars vora carreteres en ambients silicis, 8.X.2016, R. Senar (herb. pers. RS 7536). Plana Alta: Borriol, vall d'Umbrí, vora l'autovia A-7, 30TYK4835, $140 \mathrm{~m}$, cunetes, 4.XI.2016, P. Gumbau \& R. Senar; Torreblanca, vora N-340, 31TBE6156, 40 m, cunetes, 12.IX.2018, R. Senar.

Gramínia perenne que forma denses tofes de fins $130 \mathrm{~cm}$ d'alçada, és originària del nord-oest d'Àfrica, i s'estén des de Tunísia a Somàlia fins a l'extrem occidental d'Àsia (Sanz Elorza et al., 2004). Pareix que la seua introducció a la península es deu a l'ús ornamental en jardins públics i vials, de manera que contribueix a la seua ràpida expansió pels ecosistemes tèrmics ibèrics.

Dins de la península Ibèrica va ser advertida per primer colp a Alacant per Crespo et al. (1990) i Juan et al. (1995). Des d'aleshores ha sigut indicada en gairebé totes les comarques litorals valencianes (BDBCV), encara però, no havia sigut advertida a l'Alcalatén.

Cenchrus setaceus està considerada com a espècie invasora a Espanya, present en tota la costa oriental des de Castelló fins a Huelva, Menorca i en totes les Illes Canàries, on suposa un gran problema sobre els fràgils ecosistemes insulars (Sanz Elorza et al., 2004; ANTHOS).

Cotyledon macrantha A. Berger in Monatsschr. Kakteenk. 1900: 106 (1900) (Crassulaceae).

Castelló, *Alt Palància: Assuévar, part alta del poble, 30SYK2512, $300 \mathrm{~m}$, herbassars ruderals, 22.XI.2015, R. Senar \& A. Torres (herb. pers. RS 5789).

Tàxon d'origen capense, freqüent en jardineria però rar com a al·lòcton. En l'àmbit valencià, s'han citat unes poques localitats per a les províncies d'Alacant i València (Guillot et al., 2008b; Guillot \& Sáez, 2014c; BDBCV). A Castelló, únicament ha sigut advertida a la Plana Baixa i el Baix Maestrat (Roselló, 2008a; Senar, 2016). No ha estat citada a l'Alt Palància segons l'estudi de Gimeno (2005).

Crassula muscosa (L.) Roth, Enum. Pl. Phaen. Germ. 1: 994 (1827) (Crassulaceae).

= Crassula lycopodioides Lam., Encyc. 2(1): 173 (1786).

Castelló, Alt Maestrat: Vilar de Canes, carrer de Baix, junt a la carretera, 30TYK4971, $660 \mathrm{~m}$, cingles calcaris, 25.V.2017, R. Senar \& A. Torres. 
Espècie que, amplament cultivada com a ornamental i amb gran facilitat d'arrelar a partir d'esqueixos, apareix subespontània en teulades, murs, canals... En determinats llocs, manifesta un caràcter invasor i suposa una problemàtica sobre els ecosistemes naturals, com a les Illes Canàries i a certs llocs de Catalunya (Sanz Elorza et al., 2004), problemàtica que pel moment no s'ha detectat al País Valencià. S'aporta una localitat més al conjunt de dades recollides per a l'espècie dins de la flora al·lòctona valenciana.

Cylindropuntia kleiniae (DC.) F. M. Knuth in Backeb. \& F. M. Knuth, Kaktus-ABC 123 (1935) (Cactaceae).

*Castelló, Baix Maestrat: Cervera del Maestre, camí al mas de Ventura, 31TBE7184, 170 m, entre marges de finques i el camí, sobre roquers calcaris, 31.III.2017, P. Gumbau (herb. pers. RS 8150, VAL 236735).

Aquesta cactàcia es distribueix de manera natural pel sud dels EUA fins a Mèxic, i forma part del matollar xèric i llocs pertorbats de sòl calcari, entre els 1200-1500 m (Arias et al., 2012). Es coneix com a ornamental a la flora espanyola (López et al., 2000), encara que com al·lòctona s'ha citat recentment en la província de València (Guillot, 2017). S'aporta per tant la segona cita espanyola per a aquesta espècie i la primera per a la província de Castelló.

Echinopsis pachanoi (Britton \& Rose) Friedrich \& G. D. Rowley in Int. Organ. Succ. Pl. Study Bull. 3(3): 96 (1974) (Cactaceae).

$\equiv$ Trichocereus pachanoi Britton \& Rose, Cact. 2: 134-135 (1920).

*Castelló, Baix Maestrat: Benicarló, pr. basseta del Bovalar, 31TBE7778, 50 m, ermots, 9.II.2017, R. Senar; ibid., barranc de Pàndols, 31TBE7881, $60 \mathrm{~m}$, canyar vora barranc, 1.XI.2017, P. Gumbau $\&$ R. Senar; ibid., rambla de Cervera, entre els camins de Sant Jordi i Moliners, 31TBE7979, 30 $\mathrm{m}$, vores de la rambla, codolar calcari, 7.IV.2017, P. Gumbau \& R. Senar (Fig. 1); ibid., camí vell de Càlig, pr. bassa de Sales, 31TBE8078, $20 \mathrm{~m}$, vores del camí, 9.II.2017, R. Senar; ibid., rambla de Cervera, pr. cementeri, 31TBE8178, 15 m, vores ruderals, 14.III.2017, R. Senar; ibid., barranc d'Aigualiva, 31TBE8280, $10 \mathrm{~m}$, talussos ruderals sobre codolar calcari, 11.IV.2015, R. Senar

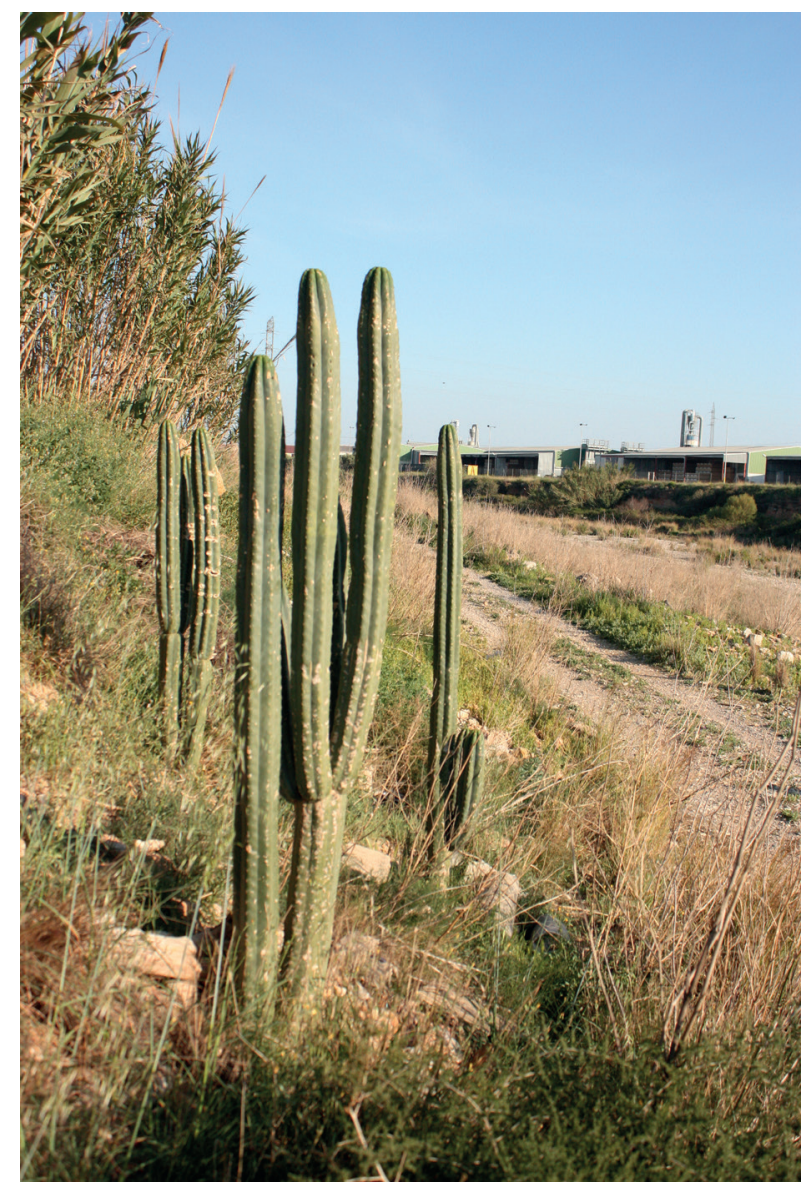

Figura 1. Echinopsis pachanoi a la rambla de Cervera, Benicarló (fotografia: R. Senar).

(herb. pers. RS 4527); Peníscola, punta de la serra, 31TBE7674, $40 \mathrm{~m}$, raconades ruderals amb restes de podes, 10.XI.2018, R. Senar. *Tarragona, Baix Ebre: Tortosa, Pasqualet, 31TBF8914, 45 m, camps erms ruderals, 10.II.2015, R. Senar.

Cap població esmentada pertany a naturalitzacions a partir d'antics cultius, sinó que totes elles provenen d'esqueixos procedents de podes, algunes de les quals amb restes prou evidents. Excepte la població de Peníscola (rebrots de $0,5 \mathrm{~m}$ ), la resta són exemplars d'entre 2-4 m d'alçada, ben desenvolupats i per tant amb diversos anys vivint al medi natural.

Echinopsis pachanoi és un cactus originari de Bolívia, Equador i Perú, conreat com a ornamental de manera freqüent a la província de Castelló (obs. pers.). Sobta que del seu cultiu a la península Ibèrica no es fasa referència dins l'obra de López et al. (2000), encara que sí que apareix en Guillot et al. (2008a) cultivat en la província de València. Pel que fa a la flora al-lòctona, només ha sigut citat 
anteriorment a València, concretament a Godella i Paterna (Laguna et al., 2013; Guillot et al., 2014), i que suposen les úniques localitats conegudes per a la península Ibèrica. S'aporten així les primeres cites d'aquest cactus per a les províncies de Castelló i Tarragona.

Euphorbia tirucalli L., Sp. Pl. 1: 452 (1753) (Euphorbiaceae).

Alacant, Baix Segura: Benferri, rambla d'Abanilla, vora barri de les Coves, 30SXH7822, 90 m, talussos xèrics, 22.VI.2018, R. Senar.

Eufòrbia arbustiva que es distribueix pel sud i est d'Àfrica. En aquesta ocasió, se l'ha pogut trobar escapada de cultiu en un ambient nitrogenat dominat per Whitania frutescens (L.) Pauquy, típica $\mathrm{d}$ 'aquestes zones xèriques.

Euphorbia tirucalli ha sigut detectada amb anterioritat en la península Ibèrica en dos localitats, Benicarló (Castelló) i Guardamar del Segura (Alacant). Aquesta darrera en la mateixa comarca del Baix Segura i a la qual s'aporta una segona cita (Mesa et al., 2008; Gómez et al., 2015).
Graptopetalum paraguayense (N. E. Br.) E. Walther in Cact. Succ. J. 9: 108 (1938) (Crassulaceae).

Castelló, *Alcalatén: Costur, mas d'Avall, 30TYK4045, $420 \mathrm{~m}$, roquers calcaris, 14.II.2016, P. Gumbau, R. Senar \& A. Torres.

Habitual en cultius, a partir dels quals pot aparèixer subespontània per les proximitats en murs, balcons o teulades. No manifesta caràcter invasor i no suposa perill per als nostres ecosistemes (Guillot et al., 2008b). Al País Valencià, la majoria de cites estan referides a la província de València (Guillot, 2001, 2003a; Guillot et al., 2015). A Castelló, ha sigut citada a Benicarló, Borriana i Vilar de Canes (Roselló, 2008b; Senar, 2016), s'aporta per tant la primera localitat per a l'Alcalatén.

Hydrocotyle verticillata Thunb., Hydrocotyle 2: 5-6, pl. s.n.[2] (1798) (Araliaceae).

*Tarragona, Montsià: Ulldecona, molí del Cilindre, basseta al pati del molí, 31TBE8196, $170 \mathrm{~m}$, herbassar hidròfil, 3.VIII.2013, S. Cardero (Fig. 2).

Població abundant en nombre d'individus, en la qual s'observa una clara propagació dins de la

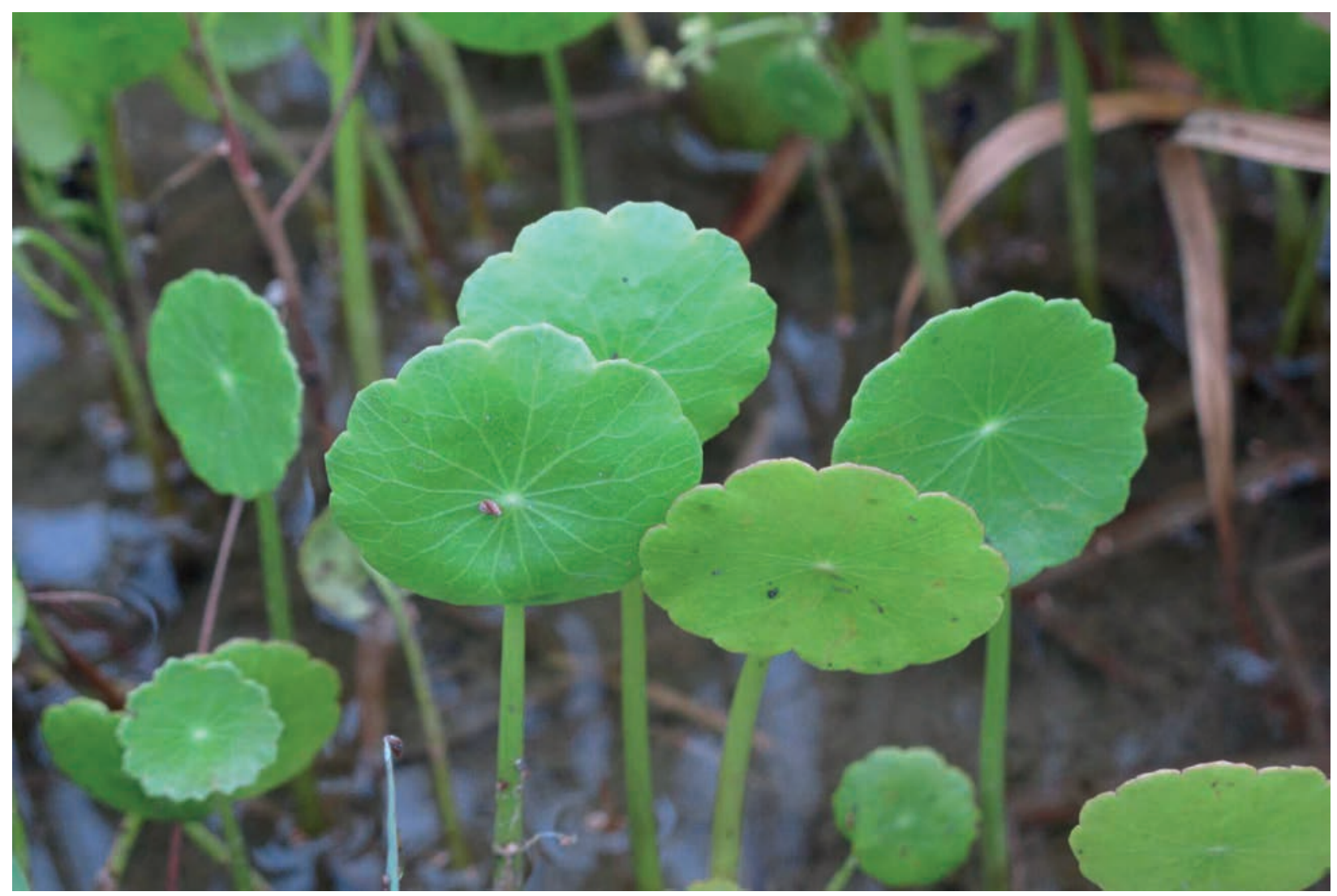

Figura 2. Hydrocotyle verticillata, molí del Cilindre, Ulldecona (fotografia: S. Cardero). 
bassa per mitjà d'estolons. Els propietaris actuals del molí desconeixen l'origen de la planta.

L'espècie és originària del continent americà, $\mathrm{i}$ es distribueix des d'EUA fins a Xile, en ambients pantanosos i fluvials. Fora de la seua zona d'origen, es comercialitza amb finalitats ornamentals com a planta d'aquari i de jardineria (Khatun et al., 2010; Díaz Pita, 2011). Ha sigut advertida naturalitzada en diversos països d'Àsia, Àfrica, Oceania i Europa segons la base de dades de Q-BANK (2019).

A la península Ibèrica, va ser indicada per primera vegada a València i Castelló (Carretero, 1997), on actualment $H$. verticillata és molt present en diversos punts de l'Albufera de València (Vera \& Valentín, 2009; BDBCV). Fora del País Valencià, ha sigut indicada més recentment a Cadis i Huelva, en les zones de maresmes de Doñana (Sánchez et al., 2009; Valdés et al., 2011). S'aporta la primera cita de l'espècie per a Catalunya ja que no es coneixen referències anteriors per a aquest territori.

Leucaena leucocephala (Lam.) De Wit in Taxon 10(2): 54 (1961) (Leguminosae).

Castelló, Baix Maestrat: Alcalà de Xivert, Alcossebre, carretera CV-142, 31TBE6559 i BE6560, $55 \mathrm{~m}$, cunetes i vores de la carretera, 31.XII.2018, R. Senar; Peníscola, serra d'Irta, urbanització Cap Blanc, 31TBE7769, $40 \mathrm{~m}$, ermots amb coscollars, 10.I.2019, R. Senar (herb. Pers. RS 11541); ibid., els Mongells, vora urbanització los Olivos, 31TBE7773, 25 m, erms, 31.XII.2018, R. Senar; ibid., els Peruns, vora entrada a l'autopista AP7, 31TBE7775, $45 \mathrm{~m}$, talussos de la carretera, 19.IV.2018, R. Senar; Benicarló, camí Moliners a la partida Carrasca, 31TBE8081, $50 \mathrm{~m}$, vores del camí amb ambient ruderal, 26.X.2017, R. Senar (herb. pers. RS 9798, VAL 236822). Tarragona, *Montsià: Ulldecona, carrer pujada al Mirador, 31TBE8691, 95 m, zones ermes, 27.XII.2015, S. Cardero.

Arbre perennifoli d'origen neotropical distribuït des del sud dels EUA fins a Guatemala. S'ha exportat com a ornamental en quasi totes les zones càlides del planeta, on malauradament apareix naturalitzat. A Espanya, es cultiva en multitud de jardins, tan privats com públics, sobretot a l'est peninsular (Sanz Elorza et al., 2004). Leucaena leucocephala està considerada invasora d'entre les 100 espècies més perilloses del ISSG (Invasive Species Specialist Group) de la UICN (2018), també com a planta al·lòctona invasora d'Espanya (Sanz Elorza et al., 2004).

La primera cita peninsular de l'espècie la trobem al treball de Casasayas (1989) on l'assenyala naturalitzada als voltant de Tarragona. A banda d'aquesta cita, L. leucocephala ha sigut trobada posteriorment a les províncies d'Almeria i Huelva (Dana et al., 2003; Sánchez Gullón et al., 2017), una segona localitat a Tarragona (Gómez-Bellver et al., 2019a), a més del País Valencià. Dins d'aquest darrer territori, existeixen un bon grapat de localitats a les províncies d'Alacant $\mathrm{i}$ València al BDBCV, mentre que a Castelló ha sigut reportada a Alcalà de Xivert, Moncofa i Vila-real (Herrero-Borgoñón, 2007; Roselló et al., 2018). Així doncs, s'aporten un conjunt de localitats més per a les províncies de Castelló i Tarragona, on resulta novetat comarcal per al Montsià.

Lophocereus marginatus (DC.) S. Arias \& Terrazas in Syst. Bot. 34(1): 82 (2009) (Cactaceae).

$\equiv$ Pachycereus marginatus (DC.) Britton \& Rose in Contr. U.S. Natl. Herb. 12(10): 421-422 (1909).

*Castelló, Baix Maestrat: Benicarló, pr. basseta del Bovalar, 31TBE7778, $50 \mathrm{~m}$, camps de garrofers abandonats, 23.IX.2017, $R$. Senar; ibid., rambla de Cervera, 31TBE8178, $10 \mathrm{~m}$, talussos ruderals sobre conglomerats calcaris, 12.XII.2015. R. Senar.

Poblacions naturalitzades a partir d'esqueixos de tiges (encara visibles) llançades juntament amb restes de podes.

Aquest cactus és originari de Mèxic on abunda en diversos estats. Es tracta d'una espècie rara en cultius i naturalitzada segons Guillot et al. (2009). Dins d'aquest treball s'indica que l'espècie s'ha vist cultivada a les províncies d'Alacant i València, no obstant, aprofitem per a confirmar que també s'ha vist cultivada en diversos jardins de la comarca del Baix Maestrat, de forma no massa rara (obs. pers.).

Lophocereus marginatus sols ha sigut detectada naturalitzada a la península Ibèrica en Teulada (Alacant), segons el treball de Laguna et al. (2014b). Així doncs, s'aporten les segones cites per aquesta cactàcia, i les primeres per a la província de Castelló.

*Manihot grahamii Hook., Icon. Pl. 6: pl. 530 (1843) (Euphorbiaceae).

Tarragona, Montsià: Ulldecona, partida de la Miliana, final del canal Xerta-Sénia, 31TBF8202, 140 


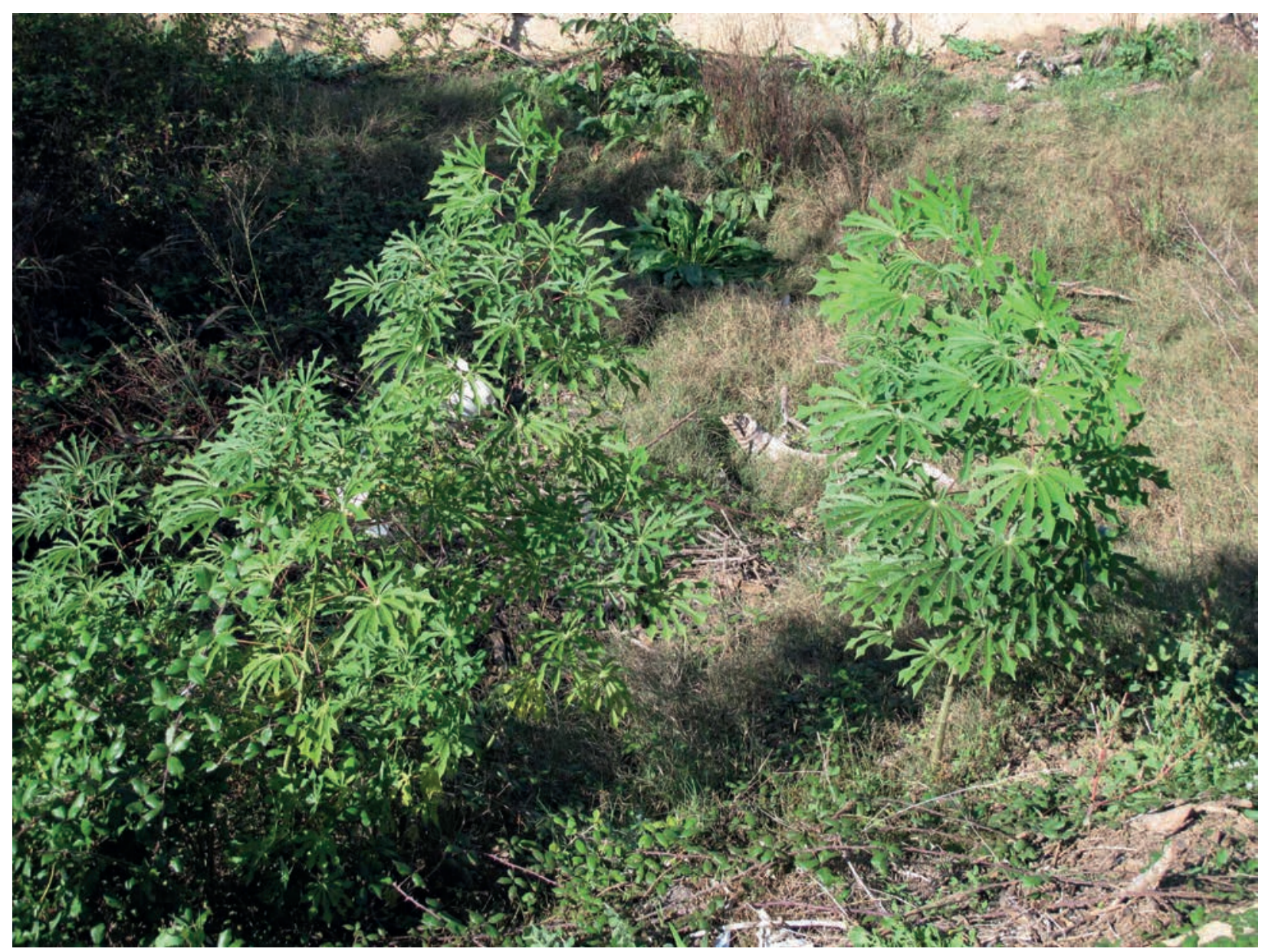

Figura 3. Manihot grahamii al fons del canal Xerta-Sénia, Ulldecona (fotografia: S. Cardero).

m, ambient ruderalitzat, 5.XI.2014, A. Vendrell \& S. Cardero (MTTE 129) (Fig. 3).

Població formada per individus de generacions diverses, que arriben a florir i fructificar els més majors. Les restes de la poda o la dispersió de llavors procedents d'un jardí proper poden ser l'origen de la població. Les seues llavors resulten del tot viables, tal i com s'ha pogut comprovar per la sembra de material procedent d'aquesta població.

El gènere Manihot és d'origen neotropical amb espècies d'importància ornamental, silvícola $\mathrm{o}$ alimentària com la iuca o mandioca (M. esculenta Crantz). Manihot grahamii es distribueix per Brasil, Argentina, Uruguai i Paraguai, en terrenys humits tan en orles de bosc com en llocs pobres en vegetació (Orlandini \& Ribes de Lima, 2014). Té un comportament caducifoli, i és l'espècie del gènere Manihot més resistent a les baixes temperatures. Les gelades poden assecar les parts aèries però rebrota bé en primavera, o inclús pot rebrotar a partir de les arrels si tota la part aèria es veu afectada.
Degut a la bellesa de les seues fulles, l'espècie es conrea fora de la seua zona d'origen com a arbre ornamental (Carrere, 2007; Hayden, 2016).

Aquesta espècie es coneix com al-lòctona almenys als EUA, Àfrica del Sud i Austràlia (Forster, 1997; Henderson, 2007; Hayden, 2016). A Europa, va ser detectada per primer colp a Itàlia (Iberite \& Iamonico, 2015) i darrerament també a Bèlgica (Verloove, 2018). Amb aquesta informació, s'aporta la primera citació de l'espècie per a la flora ibèrica.

Mortolopuntia schickendantzii (F. A. C. Weber) Guiggi in Cactology 5(Suppl.): 1 (2015) (Cactaceae).

$\equiv$ Opuntia schickendantzii F. A. C. Weber, Dic. Hort.: 898 (1898).

Castelló, Baix Maestrat: Peníscola, serra d'Irta, pla dels Pitxells, 31TBE7768, $5 \mathrm{~m}$, coscollar xèric sobre roquers calcaris, 19.IV.18, $R$. Senar; Sant Rafel, malea de Figuereta, pou del Busso, 31TBE7495, 
225 m, coscollars, 3.XI.2018, R. Senar; Vinaròs, molí Noguera, 31TBE8394, 130 m, 21.XII.2016, raconades ruderals, $P$. Gumbau \& R. Senar; Xert, mas de l'Om, 31TBE5688, $510 \mathrm{~m}$, ambients nitrogenats, 27.III.2018, R. Senar; ibid., vora l'església vella, 31TBE5989, $500 \mathrm{~m}$, coscollars antropitzats, 24.IX.2017, R. Galeote, P. Gumbau, R. Senar \& A. Torres; ibid., camí de Canet lo Roig, 31TBE6089, $450 \mathrm{~m}$, marges de finques, 27.III.2018, R. Senar.

Cactàcia originària d'Amèrica del Sud, per a la qual els darrers anys s'ha vist incrementada la seua zona de distribució a l'est de la península Ibèrica com a espècie exòtica. Va ser advertida per primera vegada a la península per Guillot \& Sáez (2014b), en la província de València. Seguidament citada també a Castelló (Vázquez, 2014), Girona (Aymerich, 2015a, 2016b), Barcelona (Gómez-Bellver et al., 2016), Alacant (Verloove et al., 2018) i també a la costa andalusa de Huelva (Sánchez Gullón et al., 2014). A la comarca del Baix Maestrat va ser citada per Senar (2016), localitats a les quals cal sumar aquestes noves.
Nicandra physalodes (L.) Gaertn., Fruct. Sem. Pl. 2: 237 (1791) (Solanaceae).

*Tarragona, Montsià: Ulldecona, partida de la Miliana, 31TBF8001, $160 \mathrm{~m}$, finca erma vora fruiters, 30.X.2014, A. Vendrell \& S. Cardero (MTTE 28) (Fig. 4).

Nicandra physalodes es considera originària de Colòmbia i Perú, encara que degut al seu cultiu es troba en altres localitats d'Amèrica. És una espècie pròpia de clima fred o lleugerament càlid que viu en altituds d'entre els 1300-2650 m, a la seua zona d'origen (González Bueno, 2004). Va ser introduïda a Europa com a ornamental al segle XVIII (Casasayas, 1989).

$N$. physalodes apareix naturalitzada pel sud d'Europa, Macaronèsia, Amèrica del Nord, Índia, Moçambic i Austràlia (Gallego, 2012). A la península Ibèrica, ha estat advertida naturalitzada a Cantàbria, Castella la Manxa, Andalusia, Madrid, Galícia, i País Basc (Gallego, 2012). A Catalunya, va ser indicada al Maresme per Casasayas (1989),

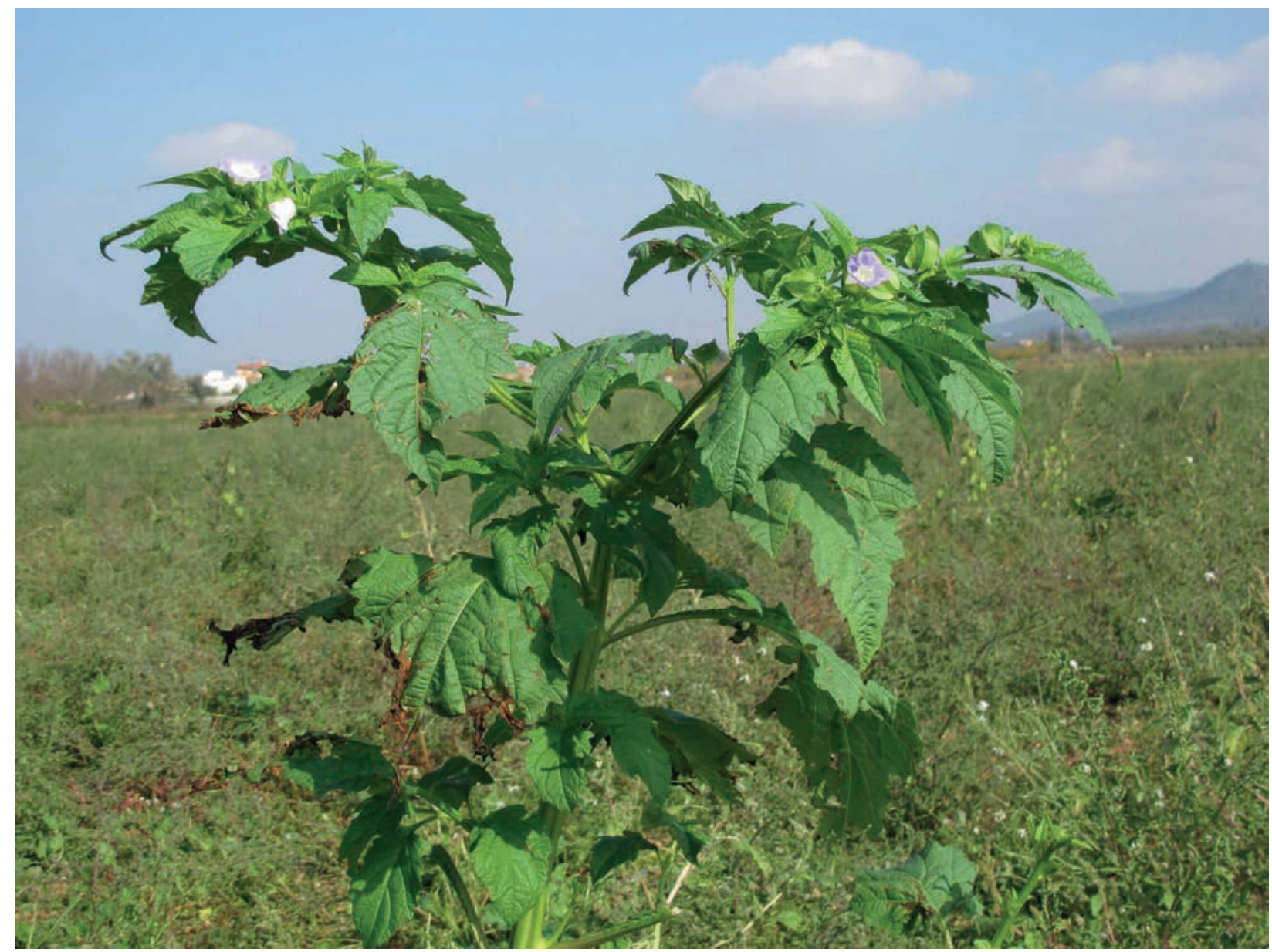

Figura 4. Nicandra physalodes a la Miliana, Ulldecona (fotografia: S. Cardero). 
on a més s'aporten les dades de dos plecs anteriors al segle XX: "Olot, 1899, ex herb. A.C. Costa (BC 613860); sense lloc de recol-lecció, 29.1.1879, ex herb. Masferrer (BC 43380)". Així doncs, s'indica amb aquestes dades la primera cita de l'espècie per a la província de Tarragona.

Opuntia aurantiaca Lindl., Edwards's Bot. Reg. 19: pl. 1606 (1833) (Cactaceae).

Castelló, Baix Maestrat: Alcalà de Xivert, carretera N-340, pr. barranc del Seguet, 31TBE6357, 45 $\mathrm{m}$, ambients ruderals vora cuneta, 21.III.2016, $R$. Senar (herb. pers. RS 6009) (Fig. 5).

Cactus de port reptant que allà on s'ha trobat ocupa de forma densa diversos metres quadrats, i arriba a dominar bona part de la vegetació. Es tracta d'un cactus originari d'Argentina, Uruguai i Paraguai (Moran et al., 1976) d'origen hibridogen incert, encara que Venter et al. (1984) plantegen com a possibles parentals Opuntia discolor Britton $\&$ Rose, i $O$. salmiana Parm. Donat aquest caràcter, $O$. aurantiaca produeix fruits sense llavors i per tant la seua multiplicació és purament vegetativa. Els seus cladodis es desprenen amb molta facilitat $i$, amb la presència d'espines barbades, s'adhereixen als animals, roba o sabates, i són dispersades.

Ha sigut introduït a Austràlia, EUA, Madagascar i Àfrica del Sud, on viu en llocs secs i subdesèrtics com la sabana, on causa grans problemes sobre la flora local. És una de les espècies invasores que ha causat més problemes en Àfrica del Sud i és considerada com una les més perilloses en Austràlia (Walters et al., 2011; CABI, 2018).

Els primers casos d'assilvestrament de l'espècie que es coneixen per a la flora europea s'han donat a la península Ibèrica, concretament a Caldes de Montbui (Barcelona), la Vall d'Uxò i Navajas (Castelló) segons es publica en Guàrdia (2016) i Vázquez \& Albiach (2016).

S'aprofita l'avinentesa per a fer la correcció de la cita publicada en Senar (2016) per a l'espècie Opuntia pestifer Britton \& Rose: "CASTELLÓN: 31TBE8076, Benicarló, el Barranquet, junto camino d'Artola, $8 \mathrm{~m}$, talud de finca yerma. $R$. Senar. 20-VII-2015; ibid. R. Senar, 5-XI-2015 (herb. pers. RS 5751, VAL 228544); 31TBE8280, Vinaròs, barranco d'Aiguadoliva, $10 \mathrm{~m}$, terraplenes ruderales sobre calizas. R. Senar. 11-IV-2015". Binomen al qual es van atribuir erròniament dues poblacions pertanyents a $O$. aurantiaca. Opuntia pestifer havia estat citada anteriorment al País Valencià únicament a la localitat castellonenca de Navajas, cita recollida dins Guillot et al. (2009), a partir del treball de Vázquez (2003), i donada a conèixer també a Vázquez (2009). Aquesta cita va ser corregida com a $O$. aurantiaca per Vázquez \& Albiach

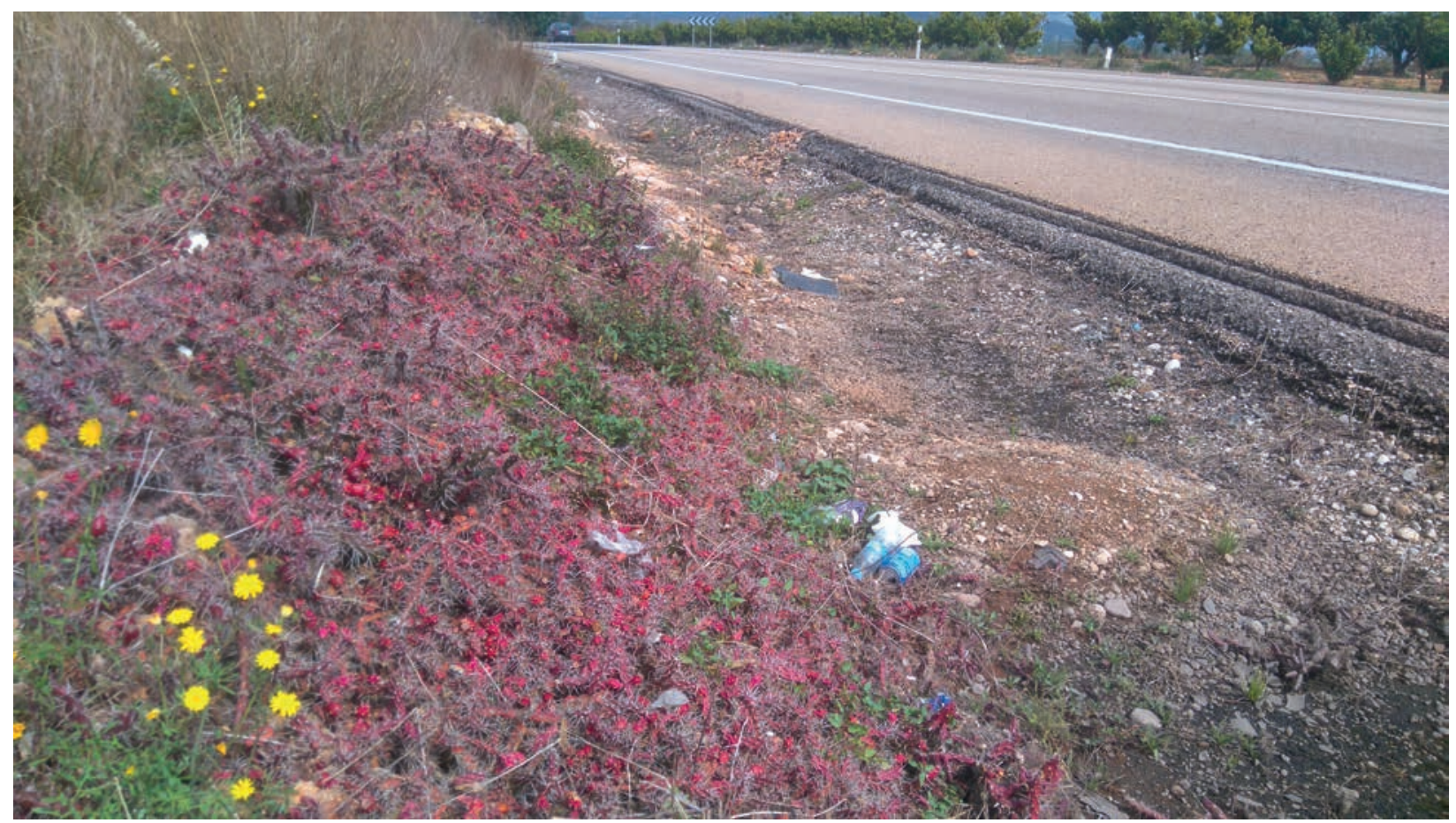

Figura 5. Opuntia auriantaca a la cuneta de la carretera N-340, Alcalà de Xivert (fotografia: R. Senar). 
(2016). Així doncs, amb la correcció també de la cita aportada per Senar (2016), queden eliminades totes les referències anteriors que es coneixien per a $O$. pestifer al País Valencià. Amb aquest fet caldria fer una correcció de les obres que tracten la flora valenciana, per tal d'eliminar $O$. pestifer com a tàxon naturalitzat.

Opuntia engelmannii var. linguiformis (Griffiths) B. D. Parfitt \& Pinkava in Madroño 35(4): 347 (1989) (Cactaceae).

= Opuntia lindheimeri var. linguiformis (Griffiths)

L. Benson in Cact. Succ. J. 41(3): 125 (1969).

Tarragona, *Montsià: Amposta, vora N-304, 31TBF9506, $10 \mathrm{~m}$, ambients ruderals vora carretera, 16.XI.2015, R. Senar (herb. pers. RS 5762).

Exemplar just a la vora de la N-340 que s'estenia uns $3 \mathrm{~m}$ vora la carretera. L'any 2016 va ser segat pels operaris de manteniment del vial, però s'ha pogut observar que dels platíclads tallats s'han tornat a produir nous exemplars. Aquest cactus ha estat citat anteriorment a Catalunya en unes poques localitats: Barcelona, Cambrils, Sant Miquel d'Aro i l'Ametlla de Mar (Sanz Elorza et al., 2006; Mallol \& Maynés, 2008; Aymerich \& Gustamante, 2015).

Opuntia microdasys (Lehm.) Pfeiff., Enum. Diagn. Cact.: 154 (1837) (Cactaceae).

Castelló, Alt Maestrat: Albocàsser, mas de Segarró, 30TYK5172, $590 \mathrm{~m}$, vores de la carretera, 21.I.2018, P. Gumbau \& R. Senar. Baix Maestrat: la Jana, carretera de Canet lo Roig, granja d'Hermini, 31TBE6788, 300 m, cunetes, 18.III.2018, R. Senar; Peníscola, serra d'Irta, font Nova, 31TBE7668, 50 $\mathrm{m}$, vores de coscollars xèrics, 21.IV.2018, R. Senar; ibid., punta de Pitxells, 31TBE7768, 2 m, coscollars vora mar, 21.IV.2018, R. Senar; Rossell, vores del poble, 31TBE6599, $470 \mathrm{~m}$, marges de finques sobre roquers calcaris, $15 . I I I .2018, R$. Senar; ibid., vora carretera de Sant Rafel, 31TBE6699, 400 m, vores de la carretera, 6.III.2018, R. Senar; Traiguera, mas de Colltort, vora camí Carretes, 31TBE7493, $220 \mathrm{~m}$, coscollars xèrics amb ambient ruderal, 29.IV.2018, R. Senar. L'Alcalatén: les Useres, pr. mas de Grau, 30TYK4754, $330 \mathrm{~m}$, vores de la carretera, 21.I.2018, P. Gumbau \& R. Senar. Plana Baixa: Moncofa, l'Estanyol, vora platja de Xilxes, 30TYK4306, 2 m, saladars, 13.III.2018, R. Senar.

Cactàcia amplament cultivada com a ornamental. S'aporten una sèrie de cites on s'ha pogut observar escapada de cultiu i que cal afegir a les localitats ja conegudes en Guillot (2003b), Guillot \& Sáez (2014a) i BDBCV.

Opuntia microdasys (Lehm.) Pfeiff., Enum. Diagn. Cact.: 154 (1837) 'Albata' (Cactaceae).

*Castelló, Baix Maestrat: Santa Magdalena de Polpis, la Canonja, vora l'autopista AP-7, 31TBE7170, $160 \mathrm{~m}$, ambients ruderals vora coscollars, 8.III.2018, R. Senar; Xert, les Forques, entrada al poble, vora el vial CV-1120, 31TBE5988, 400 $\mathrm{m}$, cunetes, 27.III.2018, R. Senar.

$S$ 'aporten una sèrie de cites referides a aquesta varietat d'Opuntia microdasys descrita per Lemke (1998-2017): “Opuntia d'1-1'8 m d'alçada, amb articles en miniatura de 7'5-15 cm de longitud i la meitat d'amplada, coberts amb moltes gloquidies blanques com la neu, semblants a pèls. Flors petites grogues de 3-6'5 cm i fruits rojos".

Es tracta d'una forma d'origen hortícola originada a partir de la var. albispina. Fobe \& Backeb (Guillot et al., 2009). S'ha cregut oportú distingir aquesta forma de la resta de congèneres ja que resulta prou notable, i sobta l'escassesa de citacions anteriors segons Guillot et al. (2009). Possiblement, algunes de les cites referides a $O$. microdasys (sensu lato) publicades fins ara corresponguen a aquesta varietat típica de cultiu. No es coneixen localitats anteriors per a la província de Castelló.

Opuntia microdasys var. albispina Fobe \& Backeb., Descr. Cact. Nov.: 10 (1956) (Cactaceae).

Castelló, Plana Baixa: Betxí, camí dels Artanencs, pont amb l'autovia A-7, 30SYK3920, $90 \mathrm{~m}$, talús de la carretera, 1.XII.2018, P. Gumbau \& R. Senar (herb. pers. RS 11524).

Tàxon paregut al precedent, s'aporta una cita més a les ja conegudes al País Valencià segons Guillot \& Meer (2001), Guillot (2003b) i Guillot et al. (2009).

Oxalis bowiei Aiton ex G. Don, Gen. Hist. 1: 761 (1831) (Oxalidaceae).

Castelló, Baix Maestrat: Càlig, pr. cementeri, extrem del camí del Socors, 31TBE7582, $100 \mathrm{~m}$, sotabosc d'oms, 10.XI.2017, P. Gumbau.

Espècie capense usada en jardineria que apareix assilvestrada a la costa mediterrània de la península Ibèrica. Al País Valencià, va ser indicada per primer colp l'any $1986 \mathrm{i}$ ha estat citada a les tres províncies 
segons Sanz Elorza et al. (2011). Pel que respecta a Castelló, es coneix a Almenara, Fondeguilla, la Llosa i la Vall d'Uixó (BDBCV). L'espècie va ser ja citada al Baix Maestrat a la localitat de Benicarló per Senar (2016).

Oxalis latifolia Kunth in Humb., Bonpl. \& Kunth, Nov. Gen. Sp. (ed. 4) 5(22): 237, tab. 467 (1822) (Oxalidaceae).

Castelló, Baix Maestrat: Vinaròs, cap a Sòl de Riu, 31TBE8988, 4 m, herbassar i canyar nitròfil vora camí, 14.X.2016, R. Senar (herb. pers. RS 7588).

Originària de d'Amèrica del Sud, s'estén de Mèxic fins a Perú, és amplament cultivada i s'ha convertit en una espècie cosmopolita pel que fa al seu assilvestrament al medi natural (Sánchez Pedraja, 2015). Al Baix Maestrat, únicament és coneix una localitat anterior a la Pobla de Benifassà (Villaescusa, 2000).

Panicum maximum Jacq., Icon. P1. Rar. 1: 2 (1781) (Gramineae).

$\equiv$ Urochloa maxima (Jacq.) R. D. Webster, Austral. Paniceae 241 (1987).

$\equiv$ Megathyrsus maximus (Jacq.) B. K. Simon \& S. W. L. Jacobs in Austrobaileya 6(3): 572 (2003).

València, Camp de Morvedre: Sagunt, vores de l'autovia A-7, 30SYJ3191, YJ3192, YJ3193, YJ3194, YJ3195, YJ3196, YJ3296, YJ3297, YJ3397 i YJ3497, 40-70 m, talussos i cunetes de la carretera, 13.XI.2016, R. Senar. *Ribera Alta: Algemesí, vores de l'autovia A-7, 30SYJ2341, YJ2342, YJ2343 i YJ2345, $20 \mathrm{~m}$, talussos de la carretera, 13.XI.2016, R. Senar. *Ribera Baixa: Almussafes, vores de l'autovia A-7, 30SYJ2256 i YJ2355, 5 m, cunetes de la carretera, 13.XI.2016, R. Senar; Benicull del Xúquer, vores de l'autovia A-7, 30SYJ2440, YJ2539 i YJ2540, $30 \mathrm{~m}$, id., 13.XI.2016, R. Senar; Corbera, vores de l'autovia A-7, 30SYJ2539, YJ2639, YJ2738, YJ2837, YJ2838 i YJ2937, 3040 m, id., 13.XI.2016, R. Senar; Favara, vores de 1'autovia A-7, 30SYJ3334, YJ3433 i YJ3434, 40-50 m, id., 13.XI.2016, R. Senar; Llaurí, vores de l'autovia A-7, 30SYJ3036, YJ3037, YJ3135, YJ3136, YJ3235, YJ3334 i YJ3335, 30-40 m, id., 13.XI.2016, R. Senar; Polinyà del Xúquer, vores de l'autovia A-7, 30SYJ2341 i YJ2440, $30 \mathrm{~m}, i d$., 13.XI.2016, R. Senar; Sollana, vores de 1'autovia A-7, 30SYJ2348, YJ2354, YJ2355 i YJ2453,
5-10 m, id., 13.XI.2016, R. Senar. La Safor: Tavernes de la Valldigna, vores de l'autovia A-7, 30SYJ3433, YJ3532, YJ3533, YJ3631, YJ3632, YJ3730，YJ3731，YJ3827，YJ3828，YJ3829, YJ3926 i YJ3927, 40-60 m, id., 13.XI.2016, R. Senar; Xeraco, vores de l'autovia A-7, 30SYJ3924, YJ3925, YJ3926, YJ4023 i YJ4024, 40-50 m, id., 13.XI.2016, R. Senar.

Planta exòtica paleotropical introduïda a la península Ibèrica com a fixadora dels talussos durant la construcció de l'autopista AP-7 (segons trams autovia A-7). És per això que la distribució $\mathrm{d}$ 'aquesta espècie està lligada al trajecte (i zones circumdants) d'aquest vial, juntament amb altres xenòfits usats amb igual finalitat com: Cenchrus ciliaris L., Chloris gayana Kunth, Cenchrus longisetus M. C. Johnst., etc. (Verloove, 2006). Fins ara $P$. maximum només s'ha localitzat en alguns trams de l'AP-7 al seu pas per Catalunya i el País Valencià. La presència d'aquesta espècie va ser advertida per Verloove (2005 ut Urochloa maxima) a Cambrils. Posteriorment es va detectar també a alguns trams de 1'AP-7 a Castelló (Verloove, 2006 ut Megathyrsus maximus; Senar, 2017), València i Alacant (Crespo et al., 2013).

$\mathrm{Amb}$ aquestes dades es donen a conèixer un seguit de punts concrets d'aquesta gramínia, situada a les vores de l'autovia A-7 al seu pas per la província de València. Per a aquesta província només es coneixia aquest tàxon a la zona de Xeresa i de Sagunt segons els treballs esmentats.

Pelargonium inquinans (L.) L'Hér., Hort. Kew. 2: 424 (1789) (Geraniaceae).

*Castelló, Baix Maestrat: Peníscola, serra d'Irta, barranc de la font Nova, 31TBE7668, 55 m, coscollars nitrogenats, 20.XI.2015, R. Senar. Plana Baixa: Betxí, muntanyeta de Sant Antoni, 120 $\mathrm{m}, 30 \mathrm{SYK} 4120$, ermots vora coscollars calcaris, 15.II.2017, P. Gumbau \& R. Senar (herb. pers. RS 7933).

Les poblacions trobades estan situades en zones bastant alterades, juntament amb altres plantes escapades de cultius. L'origen més probable és l'acumulació de restes de jardineria per l'entorn, encara que no es descarta una possible naturalització a partir d'antics cultius, especialment en la localitat de Betxí.

Pelargonium inquinans és una espècie originària d'Àfrica del Sud, que s'estén per la costa est, 
des del cap Oriental fins Kwazulu-Natal. Segons Adams (2007), P. inquinans és un arbust llenyós de fins a $2 \mathrm{~m}$, de floració durant tot l'any; fulles orbiculars amb contorn crenat o finament dentat, amb tacte de vellut $i$ amb glàndules; tiges també cobertes de vellositat $i$ amb glàndules, sent molt toves de joves $\mathrm{i}$ endurint-se amb l'edat; inflorescència formada per 5-30 flors amb pètals de coloració des del roig al rosa, inclús blanc, amb els dos pètals superiors més menuts, junts i de disposició vertical, i amb els tres restants més grans i separats; llavors 5 per flor, oblongues i prolongades amb una aresta enrotllada en espiral. La planta té gran capacitat per a arrelar a partir d'esqueixos, i és molt comuna la seua multiplicació vegetativa com a ús ornamental.

Dins de la flora europea, aquest gerani apareix naturalitzat a França, Itàlia i Portugal (Madeira) segons DAISIE (2018). Per a Espanya pareix que l'espècie, de moment, no ocasiona greus problemes com sí que ho fa el seu congènere $P$. capitatum (L.) Aiton a les Illes Canàries. No obstant, $P$. inquinans està present en bona part dels ecosistemes de La Palma, Tenerife i Gran Canària (Sanz Elorza et al., 2004). També s'ha detectat a l'illa de Menorca (Podda et al., 2010).

Segons la bibliografia, $P$. inquinans ha sigut indicada anteriorment com al·lòctona a les províncies d'Alacant i València, concretament a Alacant, Altea, el Campello, Marines i Serra (Serra, 2007; BDBCV). No es coneix cap citació anterior per a Castelló segons el BDBCV i els treballs de Samo (1995) i Villaescusa (2000).

Persicaria orientalis (L.) Spach, Hist. Nat. Vég. 10: 537 (1841) (Polygonaceae).

$\equiv$ Polygonum orientale L., Sp. Pl. 1: 362 (1753).

Tarragona, Montsià: Ulldecona, Sant Joan del Pas, canal de reg de la comunitat de regants d'Ulldecona, 31TBE8098, $180 \mathrm{~m}$, ambient subnitròfil amb humitat, 17.VIII.2015, A. Vendrell \& S. Cardero.

Planta amb ús ornamental originària del sud-est asiàtic, encara que amb una àrea de distribució natural difícil de delimitar a causa del seu cultiu des de temps antics. Avui en dia apareix des del Caucas fins al Japó i arriba fins a Austràlia oriental (Casasayas, 1989; Villar, 1990).

La primera citació peninsular és l'aportada per Sampaio (1935) a Portugal, i la primera a l'estat espanyol per Mansanet \& Aguilella (1984) a Alacant.
A Catalunya trobem les primeres cites de la seua naturalització al treball de Casasayas (1989) que la indica al Bages, el Berguedà, la Garrotxa i la Segarra. Fins aleshores ha sigut indicada en més localitats, sent més abundant a les províncies de Barcelona i Girona (BDBC). Per a Tarragona $P$. orientalis va ser indicada anteriorment per Royo (2006) al riu Sénia i als Ports, dins les quadrícules BF60 i BF70. Amb aquesta localitat d'Ulldecona s'amplia el mapa de distribució de l'espècie al sud de Catalunya.

Physalis peruviana L., Sp. Pl. (ed. 2) 2: 1670-1671 (1763) (Solanaceae).

*Castelló, Baix Maestrat: Benicarló, Sanadorlí, camí de Genaro, 31TBE8076, 15 m, herbassar nitròfil vora camí, 28.XI.2015, R. Senar (herb. pers. RS 5801); Peníscola, les Tancades, vora sèquia Templera, 31TBE7871, $5 \mathrm{~m}$, herbassars higròilis, 20.VI.2017, R. Senar; Traiguera, pr. poble, junt al camí Estret, 31TBE7089, $240 \mathrm{~m}$, herbassars nitròfils amb humitat, 12.X.2017, P. Gumbau \& R. Senar (herb. pers. RS 9773, VAL 236818). Tarragona, *Montsià: Alcanar, los Campets, vora el riu Sénia, 31TBE8689, $40 \mathrm{~m}$, herbassar ruderals amb humitat, 21.XII.2016, P. Gumbau \& R. Senar (herb. pers. RS 7800, VAL 236682).

En totes les localitats s'ha trobat un únic exemplar d'entre $50-90 \mathrm{~cm}$ d'alçada i amb flors i fruits presents. Únicament la població de Traiguera estava formada per una desena d'exemplars amb les mateixes condicions fenològiques.

Physalis peruviana és nativa del Perú, encara que alguns autors la consideren originària de Brasil i aclimatada als altiplans andins de Perú, Xile i Colòmbia, on creix entre els 1500-3000 m d'altitud. Es cultiva amb ús fructícola en diverses zones tropicals o subtropicals del món com Àfrica del Sud, Kenya, Zimbabwe, Austràlia, Nova Zelanda, Hawaii, Índia, Malàisia o Xina (Flórez et al., 2000). A Espanya, es cultiva igualment com a ornamental i com a fructícola, trobant-se naturalitzada en diversos punts de la costa mediterrània $\mathrm{i}$ cantàbrica (Sanz Elorza \& Sobrino, 2012; ANTHOS), així com a Eivissa (Guara et al., 2004). Va ser detectada a Catalunya per Costa (1877) a prop de Barcelona, presència reforçada amb més localitats recentment aportades per Aymerich (2014) i Álvarez et al. (2016), juntament amb les dades del BDBC on s'indica a les quatre províncies catalanes. Al País 
Valencià, va ser detectat a Alzira per Borja (1951), també ha sigut trobada a Alacant per Camuñas \& Crespo (1998), a més de les cites recollides dins del DBDCV.

D'acord amb la bibliografia consultada, pareix que l'espècie no es coneix a la província de Castelló, d'igual manera tampoc ha sigut citada amb anterioritat a la comarca catalana del Montsià segons Royo (2006) i el BDBC.

Podranea ricasoliana (Tanfani) Sprague, Fl. Cap. 4(2): 450 (1904) (Bignoniaceae).

*Alacant, Marina Alta: Ondara, vora N-332 cap al Verger, els Mollons, 31SBD4002, $20 \mathrm{~m}$, cunetes de la carretera, 13.XI.2016, P. Gumbau \& $R$. Senar (herb. pers. RS 7770). Castelló, *Baix Maestrat: Benicarló, Sanadorlí, camí dels Hermanos, 31TBE8176, 15 m, ermots, 28.XI.2015, R. Senar (herb. pers. RS 5802, VAL 228783); ibid., el Povet, 31TBE8177, 10 m, id., 31.III.2016, R. Senar; Peníscola, serra d'Irta, vora urbanització Cala Blanca, 31TBE7768, 40 m, erms, 7.X.2018, R. Senar.

Espècie escapada de cultiu que $s$ 'ha pogut observar en ambients similars, ermots i ambients alterats lligats a zones antropitzades. Tots aquests exemplars conformen un estrat arbustiu intricat dens $\mathrm{i}$ amb una superfície d'entre 5-15 $\mathrm{m}^{2}$.

Podranea ricasoliana és un tàxon capense de distribució molt reduïda, endèmica de la desembocadura del riu Mzimvubu, en Port St Johns, situat a la província del cap Oriental (Àfrica del Sud). Altres autors però, vacil·len en situar el seu origen per ser aquesta una espècie amplament cultivada per tot el país sud-africà (Malan \& Notten, 2002). Com a espècie ornamental s'ha convertit en cosmopolita, $\mathrm{amb}$ presència en totes les regions de clima càlid. Ha aparegut naturalitzada en Açores, Algèria, Florida, Hawaii, Puerto Rico, Xile, Austràlia i Nova Zelanda (Hurrell et al., 2012). Al País Valencià, és també coneguda com a ornamental (Guillot et al., 2008a; Guillot, 2010), on s'ha detectat naturalitzada a València i Castelló (Laguna \& Mateo, 2001; Guillot, 2003a; Laguna et al., 2014a). Per a la resta d'Espanya, ha estat citada com al·lòctona en Catalunya (Mallol \& Maynés, 2008; Gómez-Bellver et al., 2019a), Balears (Moragues, 2005; Sáez et al., 2016), Andalusia (Pérez et al., 2008) i Canàries (Otto \& Verloove, 2016).

S'aporta la primera cita per a la província d'Alacant, per a la qual no es coneixen cites anteriors segons Serra (2007) i el BDBCV. D'igual manera, s'aporten també les primeres cites per al Baix Maestrat segons els treballs de Villaescusa (2000) i Royo (2006).

Sedum pachyphyllum Rose in Contr. U.S. Natl. Herb. 13(9): 299 (1911) (Crassulaceae).

*Castelló, Alt Palància: Xóvar, carrers del poble, 30SYK2914, $350 \mathrm{~m}$, talussos silicis, 22.XI.2015, R. Senar \& A. Torres.

Crassulàcia originària de Mèxic usada com a ornamental (López et al., 2003). És estrany trobar-la naturalitzada, a la flora valenciana ha sigut citada únicament a la província de València (Guillot et al., 2008b; Guillot \& Sáez, 2014c). Així doncs, es dona a conèixer la primera localitat a la província de Castelló.

Sedum palmeri S. Watson in Proc. Amer. Acad. Arts 17: 355 (1882) (Crassulaceae).

Castelló, Alt Palància: Almedíxer, 30SYK2116, $400 \mathrm{~m}$, teulades de les cases, 22.XI.2015, R. Senar $\&$ A. Torres.

D'origen mexicà, és una planta usada com a ornamental i cultivada en totes les comarques valencianes (Guillot et al., 2008b). Ha sigut citada per a la província de València en diferents localitats on es considera rara com a al·lòctona (Guillot, 2001; Guara et al., 2004; Laguna et al., 2014b). També a Castelló s'ha indicat a Borriana (Roselló, 2008a, b) i Nules (Laguna et al., 2014b). S'aporta una cita més de l'espècie per a Castelló, que resulta nova per a la comarca de l'Alt Palància.

Sedum praealtum A. DC. in Mém. Soc. Phys. Genève 11: 445-447 (1847) (Crassulaceae).

$\equiv$ Sedum dendroideum subsp. praealtum (A. DC.) R. T. Clausen, Sedum Trans-Mex. Volcanic Belt: 70 (1959).

Castelló, *Alt Maestrat: Tírig, mas de la Morellana, 31TBE4881, 620 m, coscollars, 10.XII.2017, P. Gumbau, P. Muñoz, J. V. Sempere, R. Senar \& A. Torres; Vilar de Canes, carrer de Baix, junt a la carretera de Torre d'en Besora, 30TYK4971, 550 m, cingles calcaris, 25.V.2017, R. Senar \& A. Torres. Baix Maestrat: Peníscola, serra d'Irta, barranc de la font Nova, 31TBE7668, $55 \mathrm{~m}$, ambients ruderals vora coscollars, 20.XI.2015, R. Senar (herb. pers. RS 5775); Traiguera, els Codengraus, 31TBE6989, $315 \mathrm{~m}$, marges de finques ermes, 25.I.2019, $R$. 
Senar; Xert, mas de 1'Om, 31TBE5688, 510 m, talussos nitrogenats, 27.III.2018, R. Senar. *Alcalatén: Benafigos, voltants del poble, 30TYK3762, $940 \mathrm{~m}$, vores de camins i finques, 2.IV.2018, $P$. Gumbau, P. Muñoz, J. V. Sempere, R. Senar \& A. Torres (herb. pers. RS 10098); Costur, mas d'Avall, 30TYK4045, $420 \mathrm{~m}$, ermots vora les cases, 14.II.2016, P. Gumbau, R. Senar \& A. Torres; les Useres, voltants del poble, 30TYK4148, 370 m, erms, 14.II.2016, P. Gumbau, R. Senar \& A. Torres. Tarragona, Montsià: Ulldecona, barri Castell, els Bordales, 31TBE7598, $250 \mathrm{~m}$, marges de finques, 4.V.2011, R. Senar. Terol, *Matarranya: Pena-roja de Tastavins, lo Pont Xafat, vora poble, 31TBF5015, $770 \mathrm{~m}$, marges de finques ermes, 12.VI.2010, R. Senar.

Tàxon neotropical originari de Mèxic i Guatemala (Pérez-Calix, 2008). Es cultiva com a ornamental en gairebé tot el territori valencià (Guillot et al., 2008b), així com d'altres zones càlides de la península. A Castelló, s'ha indicat anteriorment a Castelló de la Plana, Onda, la Pobla de Benifassà i Xert (Aguilella, 1993 ut S. dendroideum; Guillot et al., 2008b; Senar, 2016; BDBCV). A Catalunya, l'espècie ja va ser observada naturalitzada pels voltants de Barcelona i Tortosa per Sennen (1916, 1929 ut S. dendroideum). També s'ha trobat a Sant Martí Sarroca, Tossa de Mar i Port de la Selva (Aymerich, 2015b, 2016b). A Terol l'espècie ha sigut indicada amb anterioritat a la localitat d'Olba (Guillot \& Meer, 2010).

Amb tot això, s'aporten noves dades d'aquesta crassulàcia per a l'est ibèric, suposant nova espècie al·lòctona per a l'Alt Maestrat, l'Alcalatén i el Matarranya. Per a Catalunya sorprèn que lluny de la poca informació bibliogràfica, hom s'hi troba dins del BDBC recollides 42 cites d'aquesta espècie, la majoria per al sud de Tarragona, Montsià i Baix Ebre. Es desconeixen localitats precises de cadascuna, encara així s'aporta una dada precisa per al Montsià.

Sedum praealtum i $S$. dendroideum són espècies molt pròximes, que de vegades s'han atribuït com a un sol tàxon. És per això que dins de Guillot et al. (2008b) i Aymerich (2015b) s'adverteix que moltes de les cites anteriors de $S$. dendroideum, en realitat corresponguen a $S$. praealtum. Ja que com els mateixos autors assenyalen, és aquesta l'espècie més conreada al territori i per tant també la més escapada de cultiu.
Senna corymbosa (Lam.) H. S. Irwin \& Barneby in Mem. New York Bot. Gard. 35: 397 (1982) (Compositae).

$\equiv$ Cassia corymbosa Lam., Encycl. 1(2): 644 (1785).

Castelló, Baix Maestrat: Càlig, rambla de Cervera, baix pont del camí Vinaròs, 31TBE7682, $85 \mathrm{~m}$, llera del riu, rebles calcaris amb humitat estacional, 17.IX.2017, R. Senar (herb. pers. RS 9673, VAL 236782); ibid., rambla de Cervera, riu avall des del Regall, 31TBE7582, 85 m, id., 13.XI.2018, R. Senar.

Tram de $800 \mathrm{~m}$ de la rambla de Cervera, des de la desembocadura del Regall fins al camp de futbol de Càlig, on s'han localitzat diversos peus d'aquest arbust. Se l'ha vist cultivat en xalets a la vora de la sèquia del Regall, que segurament han actuat com a dispersors de llavors riu avall.

Segons Bianco \& Kraus (1997 ut Cassia corymbosa), Senna corymbosa és una planta arbustiva de fins a $5 \mathrm{~m}$ d'alçada, d'origen neotropical que es distribueix des del sud de Brasil fins al centre d'Argentina. Guillot et al. (2008a) la indiquen com a ornamental a la província de València de forma mitjanament freqüent. A altres zones, com ara Catalunya, la seua presència es coneix des del segle XIX, observada per Colmeiro (1846) als jardins de Barcelona. Pel que fa la flora al-lòctona europea, $S$. corymbosa apareix naturalitzada a les Illes Canàries i Madeira, segons DAISIE (2018) i ANTHOS.

Dins del treball de Royo (2006), s'hi troben les que pareixen les primeres cites naturalitzades de l'espècie a l'est ibèric, indicada a la Galera (Montsià) i també al barranc del Triador, a la localitat valenciana de Vinaròs (Baix Maestrat). Així doncs, amb la localitat de Càlig s'aporta la segona citació per a l'espècie a la província de Castelló.

Solandra maxima (Sessé \& Moc.) P. S. Green in Bot. Mag. 176(3): 506 (1967) (Solanaceae).

*Castelló, Baix Maestrat: Benicarló, pr. basseta del Bovalar, 31TBE7778, 50 m, garroferars abandonats, 23.IX.2017, R. Senar; ibid., rambla de Cervera, pr. la mar Xica, 31TBE8277, $5 \mathrm{~m}$, talussos ruderals amb canyars, 10.I.2015, R. Senar (herb. pers. RS 4485) (Fig. 6).

Arbust escapat de cultiu que encara roman al lloc des de que va ser localitzat el primer nucli al 2015. Forma llargues tiges que es van entrellaçant amb la 


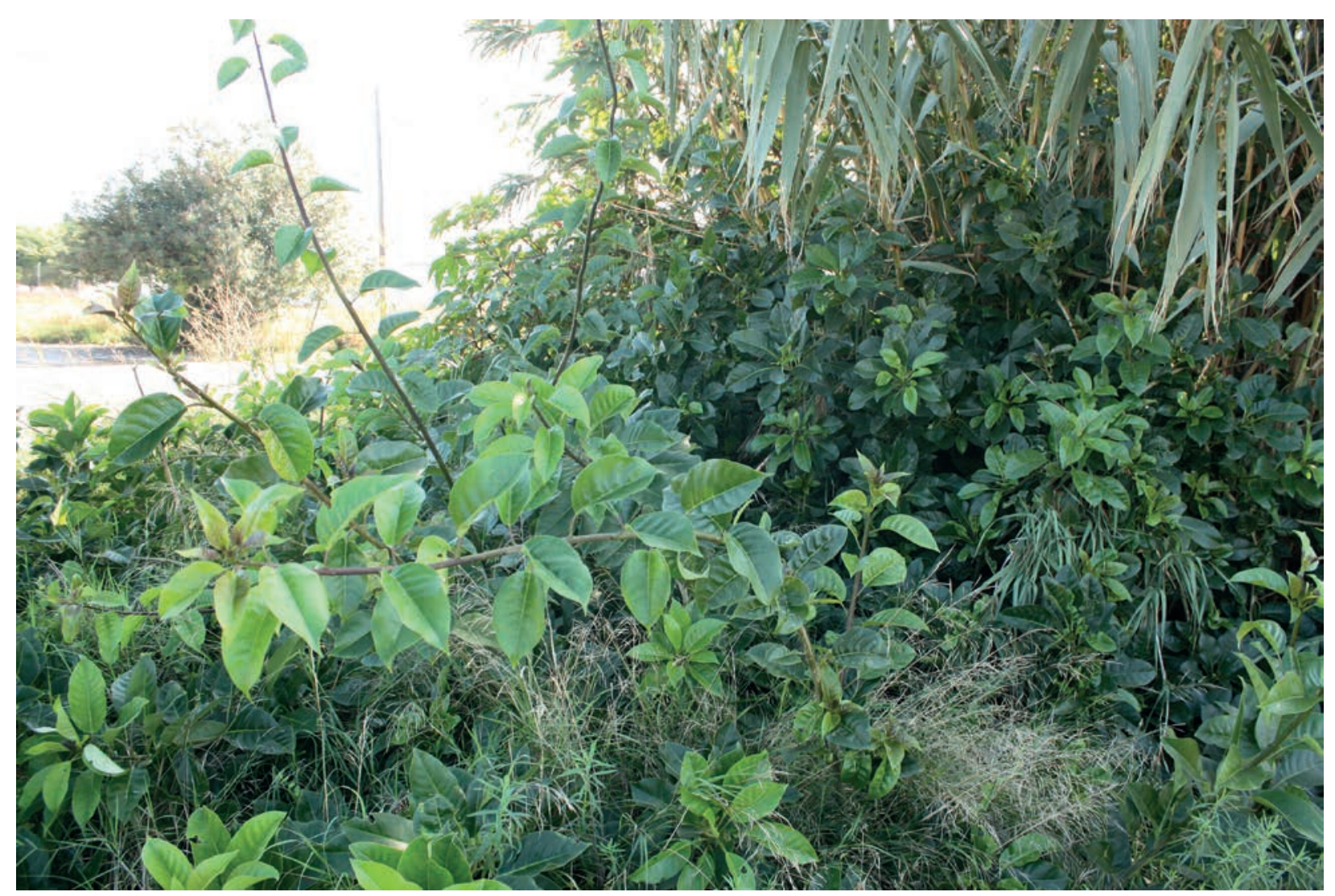

Figura 6. Solandra maxima junt als canyars de la rambla de Cervera, Benicarló (fotografia: R. Senar).

vegetació circumdant, cobrint una superfície d'uns 15-20 $\mathrm{m}^{2}$ en l'exemplar més gran.

És un arbust de caràcter trepador, de branques llargues amb lenticel·les suberoses que faciliten l'arrelament, i per tant la multiplicació vegetativa. És nativa d'Amèrica Central, des de Mèxic fins a Veneçuela, Colòmbia i Equador, on viu entre els 100 al 2300 m d'altitud, en la selva tropical i bosc mesòfil de muntanya (Ferrera \& Bye, 2011). Fora de la seua zona d'origen es cultiva com a ornamental en països de clima càlid. Com a escapada de cultiu, a Espanya ha sigut localitzada a l'illa de La Palma (Otto \& Verloove, 2016) i a nivell peninsular sols es coneix una cita anterior per a Catalunya, publicada recentment per Gómez-Bellver et al. (2019b). Dins del BDBCV s'ha detectat una cita de l'any 1993 referida a Ondara (Alacant), la qual es tracta d'una dada procedent d'un exemplar conreat en jardineria i no naturalitzat (J. X. Soler, com. pers.). Així doncs, atenent a aquesta informació s'aporten les segones localitats ibèriques per a l'espècie, i les primeres citacions valencianes com a tàxon naturalitzat.
Tradescantia fluminensis Vell., Fl. Flumin. 3: 140 (1825) (Commelinaceae).

Castelló, Baix Maestrat: Alcalà de Xivert, bassa de Vilanoves, 31TBE6461, $95 \mathrm{~m}$, canyar amb herbassar higrò̀il, 4.IV.2018, R. Senar (herb. pers. RS 10134).

Planta originària d'Amèrica del Sud, cultivada com a ornamental en quasi tots els països i naturalitzada amb molta facilitat en llocs ombrius amb certa humitat. Tradescantia fluminensis està considerada una planta invasora a diferents països com els EUA, Austràlia, Nova Zelanda, Japó, Itàlia, Portugal i Espanya. Està present en les illes macaronèsiques on ocupa zones relativament humides i envaeix ecosistemes de gran valor (Sanz Elorza et al., 2004).

Com a al·lòctona està present a les tres províncies valencianes (Sanz Elorza et al., 2011), i concretament a Castelló ha sigut citada a l'Alt Millars, 1'Alt Palància, la Plana Alta, la Plana Baixa i el Baix Maestrat (Roselló, 1994; Tirado, 1998; Villaescusa, 2000; Gimeno 2005; BDBCV). Amb aquestes dades s'aporta una localitat més per al Baix Maestrat, on va ser indicada a Rossell i Peníscola. 
Tradescantia pallida (Rose) D. R. Hunt in Kew Bull. 30(3): 452 (1975) (Commelinaceae).

$\equiv$ Setcreasea pallida Rose in Contr. U.S. Natl. Herb. 13(9): 294 (1911).

Castelló, *Alt Palància: Algímia d'Almonesir, voltants del poble, 30SYK1821, $475 \mathrm{~m}$, herbassar ruderal en terreny silici, 24.IV.2016, P. Gumbau, R. Senar \& A. Torres (herb. pers. RS 6174, VAL 230431). Baix Maestrat: Benicarló, voltants del poble, pr. ambulatori, 31TBE8176, $10 \mathrm{~m}$, erms, 31.III.2016. R. Senar. *Plana Baixa: Artana, urbanització Fuente la Higuera, 30SYK3318, 300 m, sotabosc de sureres amb humitat, ambients silicis, 4.XI.2016, P. Gumbau \& R. Senar.

Originària de Mèxic, és molt comuna com a ornamental en països de clima càlid com el nostre. Tradescantia pallida apareix naturalitzada en diversos països com l'Índia, EUA, Argentina, Nicaragua, Hondures o Espanya, entre altres (CABI, 2018). Pareix que els casos de naturalització són més escassos que l'espècie precedent, existint molt poques cites a nivell peninsular. Al País Valencià $T$. pallida ha sigut indicada a Serra i Nàquera (València), Benicarló (Castelló) i a Guardamar del Segura (Alacant) segons Guillot (2001), Senar (2016) i el BDBCV. A més a més, a l'herbari VAL existeix un plec d'aquesta espècie que l'indica naturalitzada a Cullera: "VALENNCIA: 30SYJ3741, Cullera, ermita dels Sants de la Pedra, $25 \mathrm{~m}$, erm, assilvestrat, A.P. Rivera, 29-X-2014 (VAL 225786)". Per a la resta del territori espanyol es coneix naturalitzat a Berga (Barcelona), Nerja (Màlaga) i a l'illa de la Gomera segons Talavera et al. (2010), Aymerich (2016a) i ANTHOS.

Amb aquestes dades s'aporten diverses localitats per a aquesta commelinàcia a la província de Castelló, on és novetat comarcal per a l'Alt Palància i la Plana Baixa.

Tradescantia sillamontana Matuda in Bol. Soc. Bot. México 18: 1 (1955) (Commelinaceae).

*Castelló, Alt Maestrat: Vilar de Canes, carrer de Baix, junt a la carretera de Torre d'en Besora, 30TYK4971, $550 \mathrm{~m}$, cingles calcaris, 25.V.2017, $R$. Senar \& A. Torres. Baix Maestrat: Benicarló, corral del Petiquillo, 31TBE7677, $50 \mathrm{~m}$, fenassar en clars de pinar de repoblació, 7.V.2015, R. Senar (herb. pers. RS 4880, VAL 228524).

A Benicarló es va trobar un conjunt de tiges, llançades a les immediacions d'una urbanització, les quals ja havien arrelat $\mathrm{i}$ començat a brotar. A Vilar de Canes en canvi, es va localitzar un exemplar ben desenvolupat a un talús baix les cases del poble, amb aspecte de tofa densa i en plena floració.

Tradescantia sillamontana és originària del nord-est de Mèxic i es cultiva com a ornamental a España (Sánchez de Lorenzo-Cáceres, 2016). L'espècie no apareix recollida dins la base de dades de DAISIE (2018) per a la flora al·lòctona europea. No obstant, dins l'obra Flora iberica s'indica naturalitzada "se ha encontrado en solares de la ciudad de Valencia" (Talavera et al., 2010), cita de la qual no es té més informació i no apareix als treball de Sanz Elorza et al. (2004), ni al BDBCV per a la flora valenciana. Per altra part, es coneix naturalitzada a Canàries segons Otto \& Verloove (2016) i recentment s'ha assenyalat a Catalunya per Gómez-Bellver et al. (2019a).

Així doncs, amb aquestes dades s'aporten les primeres localitats de T. sillamontana naturalitzada a la província de Castelló.

\section{AGRAÏMENTS}

Es vol expressar l'agraïment a D. Guillot per l'ajuda a l'hora d'identificar algunes cactàcies, a J. Lodé per la identificació de Echinopsis pachanoi, a J. M. Sánchez de Lorenzo-Cáceres per la informació sobre algunes generalitats de Tradescantia sillamontana. A A. Vendrell per la informació de camp i sempre disposat a mostrar algunes localitats que aquí s'aporten. També es vol agrair a J. V. Sempere per la correcció del manuscrit, i d'igual manera als editors i revisors del text per les seues aportacions.

\section{REFERÈNCIES BIBLIOGRÀFIQUES}

Adams, T. 2007. Pelargonium inquinans (L.) L'Hér. (Geraniaceae). South African National Biodiversity Institute (SANBI), Pretoria. Consultat en novembre de 2018, a http://pza. sanbi.org/pelargonium-inquinans

Aguilella, A. 1993. Datos para la flora castellonense. Anales de Biología 19 (Biología Vegetal 8): 83-89.

Álvarez, H., Ibáñez, N. \& Gómez-Bellver, C. 2016. Noves aportacions al coneixement de la flora al-lòctona de la comarca del Baix Llobregat (Catalunya, España). Collectanea Botanica 35: e007. https://doi.org/10.3989/collectbot.2016. v35.007

ANTHOS [Sistema de información de plantas de España] 2018. Real Jardín Botánico, CSIC-Fundación Biodiversidad, Madrid. Consultat en novembre de 2018, a http:// www.anthos.es

Aparicio, J. M. 2002. Aportaciones a la flora de la Comunidad Valenciana, I. Flora Montiberica 22: 48-74.

Arias, S., Gama-López, S., Guzmán-Cruz, L. U. \& Vázquez-Benítez, B. 2012.Flora del valle de Tehuacán-Cuicatlán 
(Fasc. 95, Cactaceae). Instituto de Biología (Universidad Nacional Autónoma de México), México.

Aymerich, P. 2014. Notes florístiques de les conques altes dels rius Segre i Llobregat (II). Orsis 28: 7-47. https://doi. org/10.5565/rev/orsis. 1

Aymerich, P. 2015a. Contribución al conocimiento de las cactáceas en Cataluña. Bouteloua 22: 76-98.

Aymerich, P. 2015b. Nuevos datos sobre plantas suculentas alóctonas en Cataluña. Bouteloua 22: 99-116.

Aymerich, P. 2016a. Contribució al coneixement de la flora al·lòctona del nord i centre de Catalunya. Orsis 30: 11-40. https://doi.org/10.5565/rev/orsis.26

Aymerich, P. 2016b. Notas sobre plantas alóctonas de origen ornamental en el litoral septentrional de Cataluña. Bouteloua 26: 78-91.

Aymerich, P. \& Gustamante, L. 2015. Nuevas citas de plantas alóctonas de origen ornamental en el litoral meridional de Cataluña. Bouteloua 20: 22-42.

Barnes, R. D., Filer, D. L. \& Milton S. J. 1996. Acacia karroo (Tropical Forestry Papers, 32). Oxford Forestry Institute (Department of Plant Sciences, University of Oxford), Oxford.

BDBCV [Banc de Dades de Biodiversitat de la Comunitat Valenciana] 2018. Conselleria d'Agricultura, Medi Ambient, Canvi Climàtic i Desenvolupament Rural (Generalitat Valenciana). Consultat en novembre de 2018, a http://bdb.cth.gva.es

Bianco, C. A. \& Kraus, T. A. 1997. Observaciones sobre las especies de Senna (Leguminosae-Caesalpinioideae) del sur de la provincia de Córdoba. Multequina 6: 33-47.

Bolòs, O., Font, X. \& Vigo, J. (Eds.) 2008. Atlas corològic de la flora vascular dels Països Catalans 15 (ORCA, Atlas Corològic, 15). Secció de Ciències Biològiques (Institut d'Estudis Catalans), Barcelona.

Borja, J. 1951. Estudio fitográfico de la Sierra de Corbera (Valencia). Anales del Jardín Botánico de Madrid 9: 361-483.

CABI [CAB Internacional] 2018. Invasive Species Compendium. $\mathrm{CAB}$ International, Wallingford. Consultat en novembre de 2018, a http://www.cabi.org/isc

Camuñas, E. \& Crespo, M. B. 1998. Neófitos nuevos o interesantes para la flora alicantina. Acta Botanica Malacitana 23: $210-214$.

Carrere, R. 2007. La falsa mandioca (Manihot grahamii): un arbolito nativo interesante. Consultat en gener de 2019, a http://www.guayubira.org.uy/monte/Manihot.pdf

Carretero, J. L. 1997. Hydrocotyle verticillata Thunb. (Umbelliferae) en la flora ibérica. Flora Montiberica 5: 63.

Casasayas, T. 1989. Flora al-lòctona de Catalunya, catàleg raonat de les plantes vasculars exòtiques que creixen sense cultiu al NE de la Península Ibèrica. Tesi Doctoral, Universitat de Barcelona, Barcelona.

Castroviejo, S. (Coord.) 1986-2018. Flora iberica. Plantas vasculares de la Península Ibérica y Baleares. Real Jardín Botánico (CSIC), Madrid.

Celesti-Grapow, L., Alessandrini, A., Arrigoni, P. V. et al. 2009. Inventory of the non-native flora of Italy. Plant Biosystems 143:386-430.https://doi.org/10.1080/11263500902722824

Colmeiro, M. 1846. Catálogo metódico de plantas observadas en Cataluña. Ed. vda. e hijos de Antonio Calleja, Madrid.

Costa, A. C. 1877. Introducción a la Flora de Cataluña y catálogo razonado de las plantas observadas en esta región. Imprenta Diario de Barcelona, Barcelona.

Crespo, M. B., Manso, M. L. \& Mateo, G. 1990. Pennisetum setaceum (Poaceae), especie nueva para el continente europeo. Anales del Jardín Botánico de Madrid 47: 260.
Crespo, M. B., Martínez, M. \& Camuñas, E. 2013. Novedades corológicas para la flora valenciana. Flora Montiberica 55: $118-127$.

DAISIE [Delivering alien invasive species inventories in Europe] 2018. Consultat en novembre de 2018, a www.europe-aliens.org

Dana, E. D., Randall, R. P., Sanz-Elorza, M. \& Sobrino, E. 2003. First evidences of the invasive behaviour of Leucaena leucocephala in Europe. Oryx 37: 14.

Díaz Pita, M. P. 2011. Revisión taxonómica del género Hydrocotyle L. (Apiaceae) para Colombia. Universidad Nacional de Colombia, Bogotá. Consultat en novembre de 2018, a http://bdigital.unal.edu.co/4458/1/190299.2011_pte_1.pdf

Ferrera, O. \& Bye, R. A. 2011. El género Solandra Sw. (Solanaceae) en Mesoamérica. Lacandonia 5: 43-80.

Flórez, V. J., Fischer, G. \& Sora, A. D. 2000. Producción, poscosecha y exportacion de la Uchuva (Physalis peruviana L.). Universidad Nacional de Colombia, Bogotá. Consultat en octubre de 2018, a http://www.bdigital.unal.edu. co/48034/2/9588051746.PDF

Font, X. 2018. Mòdul Flora i Vegetació. Banc de Dades de Biodiversitat de Catalunya (BDBC). Generalitat de Catalunya \& Universitat de Barcelona, Barcelona. Consultat en novembre i desembre de 2018, a http://biodiver.bio.ub.es/ biocat/homepage.html

Forster, P. I. 1997. Notes on the naturalised Flora of Queensland, 3. Austrobaileya 5: 113-119.

Gallego, M. J. 2012. Nicandra Adans. In: Talavera, S., Andrés, A., Arista, M. et al. (Eds.), Flora iberica 11. Real Jardín Botánico, CSIC, Madrid: 209-211.

Gimeno, R. 2005. Catálogo florístico, etnobotánica y plantas medicinales de la comarca del Alto Palancia. Diputació de Castelló, Castelló de la Plana.

Gómez, M. A., Laguna, E. \& Guillot, D. 2015. Primera cita de Euphorbia tirucalli L. (Euphorbiaceae) como planta alóctona en la Península Ibérica y Europa. Bouteloua 21: $52-56$.

Gómez-Bellver, C., Álvarez, H., Nualart, N., Ibáñez, N., Sáez, L. \& López-Pujol, J. 2019a. New records of alien vascular plants in Catalonia (NE Iberian Peninsula). Collectanea Botanica 38: e004. https://doi.org/10.3989/collectbot.2019.v38.004

Gómez-Bellver, C., Álvarez, H. \& Sáez, L. 2016. New contributions to the knowledge of the alien flora of the Barcelona province (Catalonia, Spain). Orsis 30: 167-189. https://doi. org/10.5565/rev/orsis.36

Gómez-Bellver, C., Nualart, N., Ibáñez, N., Burguera, C., Álvarez, H. \& López-Pujol, J. 2019b. Noves dades per a la flora al·lòctona de Catalunya i el País Valencià. Butlletí de la Institució Catalana d'Història Natural 83: 23-40. https:// doi.org/10.2436/20.1502.01.2

González Bueno, A. (Coord.) 2004. Solanáceas 38(1). In: Flora de la Real Expedición Botánica del Nuevo Reino de Granada (1783-1816). Instituto de Cultura Hispánica, Madrid: $57-58$.

Guara, M., Ferrer, P. P., Ciurana, M. J. \& Herrero-Borgoñón, J. J. 2004. Flora alóctona adventicia o naturalizada en la Comunidad Valenciana e Islas Baleares. Flora Montiberica 27: 15-22.

Guàrdia, L. 2016. On the presence of Opuntia auriantiaca (Opuntioideae, Cactaceae) in Catalonia (northeastern Iberian Peninsula). Orsis 30: 3-9. https://doi.org/10.5565/ rev/orsis. 31

Guillot, D. 2001. Apuntes sobre algunos neófitos de la flora valenciana. Flora Montiberica 18: 19-21. 
Guillot, D. 2003a. Apuntes corológicos sobre neófitos de la flora valenciana. Flora Montiberica 23: 13-17.

Guillot, D. 2003b. Sobre la presencia de 17 táxones de la familia Cactaceae en la Comunidad Valenciana. Flora Montiberica 24: 6-13.

Guillot, D. 2010. Apuntes para una flora ornamental de la comarca de la Marina Baixa. Sarrià 4: 61-66.

Guillot, D. 2017. Primera cita de Cylindropuntia kleiniae (DC.) F. M. Knuth en la Península Ibérica. Collectanea Botanica 36: e002. https://doi.org/10.3989/collectbot.2017.v36.002

Guillot, D., Ferrer-Gallego, P. P., Ferrando, I. \& Laguna E. 2014. New records of allochthonous succulent plants of ornamental origin in the province of Valencia (Valencian Community, Spain). Xerophilia 3: 62-66.

Guillot, D., Laguna, E \& Rosselló, J. A. 2008a. Claves para la flora ornamental de la provincia de Valencia (Monografías de Bouteloua, 1). Flora Montiberica, València

Guillot, D., Laguna, E \& Rosselló, J. A. 2008b. La familia Crassulaceae en la flora alóctona valenciana (Monografías de Bouteloua, 4). Flora Montiberica, València.

Guillot, D., Laguna, E. \& Rosselló, J. A. 2008c. La familia Aloaceae en la flora alóctona valenciana (Monografías de Bouteloua, 6). Flora Montiberica, València.

Guillot, D., Laguna, E. \& Rosselló, J. A. 2009. Flora alóctona valenciana: familia Cactaceae (Monografías de Bouteloua, 5). Flora Montiberica, València.

Guillot, D. \& Meer, P. van der 2001. Siete taxones nuevos del género Opuntia Mill. en la provincia de Valencia: aspectos históricos, ecológicos y reproductivos. Flora Montiberica 19: $37-44$

Guillot, D. \& Meer, P. van der 2005. Nuevos datos de las familias Agavaceae y Aloaceae en la costa mediterránea de la Península Ibérica. Flora Montiberica 30: 3-8.

Guillot, D. \& Meer, P. van der 2010. Nuevos taxones vegetales alóctonos de jardinería en el área continental de NE de España: comportamiento e historia. Management of Biological Invasions 1: 6-12. http://dx.doi.org/10.3391/ mbi.2010.1.1.03

Guillot, D., Rosselló, J. A., Laguna, E. \& Gómez, M. A. 2015. Algunas citas de neófitos en la costa peninsular española. Bouteloua 20: 100-123.

Guillot, D. \& Sáez, L. 2014a. Nuevas citas de Opuntioideas (Cactaceae) en el este de la Península Ibérica. Bouteloua 17: 116-125.

Guillot, D. \& Sáez, L. 2014b. Primera cita como alóctona de Opuntia schickendantzii F. A. C. Weber en Europa. Bouteloua 18: 3-12.

Guillot, D. \& Sáez, L. 2014c. Nuevas citas de Crasuláceas alóctonas en la costa mediterránea peninsular. Bouteloua 19: 33-49.

Hannan-Jones, M. A. \& Playford, J. 2002. The biology of Australian weeds 40. Bryophyllum Salisb. species. Plant Protection Quarterly 17: 42-57.

Hayden W. J. 2016. Manihot. In: Flora of North America Editorial Committee (Ed.), Flora of North America North of Mexico 12. Oxford University Press, New York \& Oxford: 192-196. Consultat en novembre de 2018, a http://www.efloras.org/florataxon.aspx?flora id=1\&taxon id=11961

Henderson, L. 2007. Invasive, naturalized and casual alien plants in southern Africa: a summary based on the Southern African Plant Invaders Atlas (SAPIA). Bothalia 37: 215-248. https://doi.org/10.4102/abc.v37i2.322

Herrero-Borgoñón, J. J. 2007. Dos mimosoideas (Leguminosae) nuevas para la flora castellonense. Flora Montiberica 37: 26-28.
Hurrell, J. A., Cabanillas, P. A., Buet, F. \& Delucchi, G. 2012. Bignoniaceae adventicias en Argentina. Primera cita de Podranea ricasolina y nuevos registros de Campsis radicans. Revista del Museo Argentino de Ciencias Naturales 14: 15-22. https://doi.org/10.22179/REVMACN.14.207

Iberite, M. \& Iamonico, D. 2015. Manihot grahamii Hook. (Euphorbiaceae), a new alien species for the Eurasian area with monenclatural, taxonomical, morphological and ecological notes. Acta Botanica Croatica 74: 143-150. https:// doi.org/10.1515/botcro-2015-0007

Juan, A., Serra, L. \& Crespo, M. B. 1995. Adiciones a la flora alicantina. Acta Botanica Malacitana 20: 284-290.

Khatun, B. M. R., Rahman, O. \& Sultana, S. S. 2010. Hydrocotyle verticillata Thunb. (Apiaceae) - A new angiospermic record for Bangladesh. Bangladesh Journal of Plant Taxonomy 17: 105-108. https://doi.org/10.3329/bjpt.v17i1.5398

Laguna, E., Ferrer, P. P., Deltoro, V., Ferrando, I. \& Guillot, D. 2013. Echinopsis pachanoi (Britton \& Rose) H. Friedrich \& G. D. Rowley (Cactaceae) primera cita como alóctona en España. Bouteloua 16: 34-35.

Laguna, E., Ferrer, P. P., Guillot, D. \& Roselló, R. 2014a. Sobre algunas especies capenses asilvestradas en tierras valencianas III. Bouteloua 18: 106-115.

Laguna, E., Guillot, D., Roselló, R., Gómez, M. A., Ferrer, P. P., Deltoro, V. \& Pérez P. 2014b. Nuevas citas de plantas alóctonas suculentas asilvestradas en la Comunidad Valenciana. Bouteloua 18: 141-159.

Laguna, E. \& Mateo, G. 2001. Observaciones sobre la flora alóctona valenciana. Flora Montiberica 18: 40-44.

Lemke, C. 1998-2017. Opuntia microdasys 'Albata'. Cal's Plant of the Week. University of Oklahoma. Consultat en novembre de 2018, a http://www.Plantoftheweek.org

López, A., Trigo, M. M., Argimón, X. \& Sánchez de Lorenzo-Cáceres, J. M. 2000. Flora ornamental española. Las plantas cultivadas en la España peninsular e insular 2. Mundi-Prensa, Madrid.

López, A., Trigo, M. M., Argimón, X. \& Sánchez de Lorenzo-Cáceres, J. M. 2003. Flora ornamental española. Las plantas cultivadas en la España peninsular e insular 3. Mundi-Prensa, Madrid.

Malan, C. \& Notten, A. 2002. Podranea ricasoliana (Tanf.) Sprague (Bignoniaceae). South African National Biodiversity Institute (SANBI), Pretoria. Consultat en novembre de 2018, a http://pza.sanbi.org/podranea-ricasoliana

Mallol, A. \& Maynés, J. 2008. Nous xenòfits al Baix Empordà (Catalunya). Acta Botanica Barcinonensia 51: 59-78.

Mansanet, J. \& Aguilella, A. 1984. Notas florísticas valencianas, VI. Lazaroa 6: 287-289.

Mateo, G. 2013. De flora valentina, XII. Flora Montiberica 55: 86-96.

Mateo, G. \& Crespo, M. B. 2003. Manual para la determinación de la flora valenciana (Monografías de Flora Montiberica, 4). València.

Mateo, G. \& Crespo, M. B. 2009. Manual para la determinación de la flora valenciana (Monografías de Flora Montiberica, 5). València.

Mateo, G. \& Crespo, M. B. 2014. Claves ilustradas para la flora valenciana (Monografías de Flora Montiberica, 6). Jaca.

Mesa, D., Moro, J. \& Royo, F. 2008. Notes botàniques per al Baix Maestrat $\mathrm{i}$ àrees veïnes. Toll Negre 10: 51-59.

Mesquida, V., Gómez-Bellver, C., Guillot, D., Herrando-Moraira, S., Nualart, N., Sáez, L. \& López-Pujol, J. 2017. El gènere Kalanchoe (Crassulaceae) a Catalunya: situació i 
distribució potencial del tàxon invasor $K$. $\times$ houghtonii. Orsis 31: 37-64. https://doi.org/10.5565/rev/orsis.42

Moragues, E. 2005. Flora alóctona de las Islas Baleares. Ecología de dos especies invasoras: Carpobrotus edulis \& Carpobrotus aff. acinaciformis. Tesi Doctoral, Universitat de les Illes Balears, Palma de Mallorca.

Moran, V. C., Zimmermann, H. G. \& Annecke, D. P. 1976. The identity and distribution of Opuntia aurantiaca Lindley. Taxon 25: 281-287. https://doi.org/10.2307/1219455

Orlandini, P. \& Ribes de Lima, L. 2014. Sinopse do gênero Manihot Mill. (Euphorbiaceae) no estado de São Paulo, Brasil. Hoehnea 41: 51-60. https://doi.org/10.1590/S223689062014000100005

Otto, R. \& Verloove, F. 2016. New xenophytes from La Palma (Canary Islands, Spain), with emphasis on naturalized and (potentially) invasive species. Collectanea Botanica 35: e001. https://doi.org/10.3989/collectbot.2016.v35.001

Pérez, F. J., Jiménez, M. L., Garrido, J. A. et al. 2008. Aportaciones al catálogo xenofítico de la provincia de Almería (Sureste Ibérico, España). Anales de Biología 30: 9-15.

Pérez-Calix, E. 2008. Crassulaceae. In: Flora del Bajío y regiones adyacentes (Fasc. 156). Instituto de Ecología A. C., Centro Regional del Bajío, México. Consultat en octubre de 2018, a http://inecolbajio.inecol.mx/floradelbajio/documentos/fasciculos/ordinarios/Crassulaceae\%20156.pdf

Podda, L., Fraga, P., Mayoral, O., Mascia, F. \& Bacchetta, G. 2010. Comparación de la flora exótica vascular en sistemas de islas continentales: Cerdeña (Italia) y Baleares (España). Anales del Jardín Botánico de Madrid 67: 157-176. https:// doi.org/10.3989/ajbm.2251

Pyke, S. 2008. Contribución al conocimiento de la flora catalana. Collectanea Botanica 27: 95-104. https://doi. org/10.3989/collectbot.2008.v27.8

Q-BANK [Comprehensive data base on quarantine plant pest and diseases] 2019. Consultat en gener de 2019, a http:// www.q-bank.eu/Plants/

Rosell, P., Galán, V. \& Hernández P. M. 1997. Cultivo del chirimoyo en Canarias. Departamento de Fruticultura Tropical, Instituto Canario de Investigaciones Agrarias (ICIA), Gobierno de Canarias. Consultat en octubre de 2018, a http://www.frutvasf.univasf.edu.br/images/chirimoyo.pdf

Roselló, R. 1994. Catálogo florístico y vegetación de la comarca natural del Alto Mijares (Castellón). Diputació de Castelló, Castelló de la Plana.

Roselló, R. 2008a. Forasters vindran... que a casa es quedaran (flora rupícola suculenta de les nostres teulades). Buris-ana 205: 21-25.

Roselló, R. 2008b. Flora rupícola borrianenca (i II). Buris-ana 206: 25-28.

Roselló, R., Laguna, E. \& Guillot, D. 2018. Una nueva cita de Leucaena leucocephala (Lam.) De Wit en la provincia de Castellón. Bouteloua 27: 79-80.

Roselló, R. \& Peris, J. B. 1990. Algunos neófitos de la provincia de Castellón. Fontqueria 28: 53-56.

Royo, F. 2006. Flora $i$ vegetació de les planes i serres litorals compreses entre el riu Ebro i la serra d'Irta. Tesi Doctoral, Universitat de Barcelona, Barcelona.

Sáez, L., Serapio, J., Gómez-Bellver, C., Ardenghi, N. M. G., Guillot, D. \& Rita, J. 2016. New records in vascular plants alien to the Balearic Islands. Orsis 30: 101-131. https://doi. org $/ 10.5565 /$ rev/orsis. 38

Samo, A. J. 1995. Catálogo florístico de la provincia de Castellón. Diputació de Castelló, Castelló de la Plana.
Sampaio, G. 1935. Novas adições e correcções a Flora Portuguesa. Boletim da Sociedade Broteriana 10: 216-248.

Sánchez, I., García-de-Lomas, J. \& Dana, E. 2009. Aportaciones al conocimiento de la xenoflora gaditana. Lagascalia 29: $296-313$.

Sánchez de Lorenzo-Cáceres, J. M. 2016. Especies del género Tradescantia cultivadas en España. Consultat en novembre de 2018, a https://www.arbolesornamentales.es/Tradescantia.htm

Sánchez Gullón, E., Guillot, D. \& Löde, J. 2014. Notas sobre cuatro cactáceas interesantes para la xenoflora española. Acta Botanica Malacitana 39: 242-245.

Sánchez Gullón, E., Verloove, F. \& Silva, V. 2017. New records of interesting xenophytes in the Iberian Peninsula, VII. Folia Botanica Extremadurensis 11: 39-50.

Sánchez Pedraja, O. 2015. Oxalis L. In: Muñoz Garmendia, F., Navarro, C., Quintanar, A. \& Buira, A. (Eds.), Flora iberica 9. Real Jardín Botánico, CSIC, Madrid: 383-405.

Sanz Elorza, M., Dana, E. D. \& Sobrino, E. 2004. Atlas de las plantas alóctonas invasoras de España. Dirección General para la Biodiversidad, Ministerio de Medio Ambiente, Madrid.

Sanz Elorza, M., Dana, E. D. \& Sobrino, E. 2006. Futher naturalised Cactaceae in northeastern Iberian Peninsula. Anales del Jardín Botánico de Madrid 63: 7-11. https://doi. org/10.3989/ajbm.2006.v63.i1.14

Sanz Elorza, M., Guillot, D. \& Deltoro, V. 2011. La flora alóctona en la Comunidad Valenciana. Botanica Complutensis 35: 97-130. https://doi.org/10.5209/rev BOCM.2011. v35.10

Sanz Elorza, M. \& Sobrino, E. 2012. Physalis L. In: Talavera, S., Andrés, C., Arista, M. et al. (Eds.), Flora iberica 11. Real Jardín Botánico, CSIC, Madrid: 204-209.

Senar, R. 2016. Nuevos datos para la flora alóctona valenciana. Bouteloua 23: 118-140.

Senar, R. 2017. Aportaciones a la flora castellonense, VIII. Flora Montiberica 67: 44-51.

Sennen, F. 1916. Liste des plantes observées aux alentours d'Igualada por [sic] D. Ramón Queralt Gili, étudiées et publiées par le frère Sennen; précedée de la liste des principales espèces adventices naturalisées autour de Barcelone. Boletín de la Sociedad Aragonesa de Ciencias Naturales 15: 94-105.

Sennen, F. 1929. Quelques espèces adventices, subspontanées ou cultivées en Espagne et dans le domaine méditerranéen. Cavanillesia 2: 10-42.

Serra, L. 2007. Estudio crítico de la flora vascular de la provincia de Alicante: aspectos nomenclaturales, biogeográficos y de conservación (Monografías del Real Jardín Botánico Ruizia, 19). CSIC, Madrid.

Talavera, S., Gallego, M. J. \& Herrero, A. 2010. Commelinaceae. In: Talavera, S., Gallego, M. J., Romero Zarco, C. \& Herrero, A. (Eds.), Flora iberica 17. Real Jardín Botánico (CSIC), Madrid: 118-121.

Tirado, J. 1998. Flora vascular de la comarca de la Plana Alta. Diputació de Castelló, Castelló de la Plana.

UICN [International Union for Conservation of Nature] 2018. Consultat en novembre de 2018, a https://www.iucn.org

Valdés, B., Melero, D. \& Girón V. 2011. Plantas americanas naturalizadas en el territorio de Doñana (SO de la Península Ibérica). Lagascalia 31: 7-20.

Vázquez, J. R. 2003. Flora de Navajas, Gaibiel y el pantano del Regajo. Trabajo de Investigación, Facultad de Farmacia (Universitat de València), València. 
Vázquez, J. R. 2009. Contribución al conocimiento de la flora del Alto Palancia (Castellón). Flora Montiberica 42: 83-85.

Vázquez, J. R. 2014. Nuevas citas de Opuntiodeas (Cactaceae) en la provincia de Castellón (España). Bouteloua 19: 65-70.

Vázquez, J. R. \& Albiach, X. 2016. Adiciones y correcciones a la flora alóctona de la provincia de Castellón: Cactáceas. Bouteloua 24: 3-10.

Venter, H. A. van de, Hosten, L., Ubke, R. A. \& Palmer, A. R. 1984. Morphology of Opuntia aurantiaca (jointed cactus) biotypes and its close relatives, Opuntia discolor and Opuntia salmiana (Cactaceae). South African Journal of Botany 3: 321-339. https://doi.org/10.1016/S00224618(16)30021-3

Vera, P. \& Valentín, A. 2009. Flórula y vegetación de "els ullals de na Molins" (la Albufera, Valencia). Referencia de un estado intermedio de restauración de humedales. Flora Montiberica 42: 31-40.

Verloove, F. 2005. New records of interesting xenophytes in Spain. Lazaroa 26: 141-148
Verloove, F. 2006. Exotic grasses running wild: Megathyrsus maximus var. pubiglumis (Poaceae, Paniceae) - new to Spain. Bouteloua 1: 55-60.

Verloove, F. 2018. Manihot grahamii Hook. Manual of the alien plants of Belgium. Consultat en gener de 2019, a http:// alienplantsbelgium.be/taxonomy/term/6415/descriptions

Verloove, F., Guillot, D. \& Guiggi, A. 2018. New records of interesting, non-native succulents from Alicante (Spain). Xerophilia 23: 32-42. https://doi.org/10.2985/026.023.0111

Villaescusa, C. 2000. Flora vascular de la comarca del Baix Maestrat. Diputació de Castelló, Castelló de la Plana.

Villar, L. 1990. Polygonum L. In: Castroviejo, S., Laínz, M., López González, G., Montserrat, P., Muñoz Garmendia, F., Paiva, J. \& Villar, L. (Eds.), Flora iberica 2. Real Jardín Botánico (CSIC), Madrid: 571-586.

Walters, M., Figueiredo, E., Crouch, N. R., Winter, P. J. D., Smith, G. F., Zimmermann, H. G. \& Mashope, B. K. 2011. Naturalised and invasive succulents of southern Africa (Abc Taxa, 11). The Belgian Development Cooperation, Brussels. 